\title{
Imbalance of Vitamin B Factors
}

\author{
The Effect of Conditioned Pyridoxin Deficiency on the \\ Development of Young Rats \\ BY MARION B. RICHARDS \\ Rowett Research Institute, Bucksburn, Aberdeenshire
}

(Received 9 August I948)

Previous experiments (Richards, 1945) showed that excess of vitamin $B_{1}$ in a diet rather low in the vitamin B complex caused deficiency of another vitamin B factor, pyridoxin. The deficiency, which appeared to be accentuated by addition to the diet of calcium carbonate (chalk), became manifest during the lactation period, when the suckling young developed convulsive fits characteristic of pyridoxin deficiency. No evidence of the deficiency had been apparent during the growth of the young rats before mating. It was decided, therefore, to increase the intakes of vitamin $B_{1}$ and chalk still further, in order to find whether the resulting accentuation of the dietary imbalance would elicit obvious differences between the groups of animals during their growth. From this experiment arose the present series of investigations dealing mainly with the effect of pyridoxin on the thymus development of suckling rats, under conditions of pyridoxin deficiency induced by excessive amounts of vitamin $B_{1}$ in the diet.

A short account of part of the present investigation was communicated to the Biochemical Society (Richards, 1946).

Since the growth test with the increased intakes of vitamin $B_{1}$ and chalk still showed no obvious differences between the groups, the animals were mated to find whether these increases would accentuate the effects previously observed on breeding and lactation. While the breeding tests were in progress, Stoerk \& Zucker (1944), who had fed young rats after weaning on diets lacking in one or other of four vitamin $B$ factors, reported atrophy of the thymus after 4 weeks of experiment, the atrophy being greater when pyridoxin was lacking than when vitamin $B_{1}$, riboflavin or pantothenic acid was absent. This suggested that the conditioned pyridoxin deficiency produced by excess of vitamin $B_{1}$ might have an effect on the development of the thymus gland in the stage before weaning. The thymus glands of the young rats in subsequent litters were accordingly weighed at weaning. When it became evident that pyridoxin had a marked effect in preventing atrophy of the thymus in the young rats, a further experiment was made to determine whether this effect was specific for pyridoxin, or whether a similar result would be obtained by the addition of any other single vitamin $B$ factors to the diet, unbalanced by its excessive content of vitamin $B_{1}$. The specificity of pyridoxin for thymus development in young rats after weaning was proved by Stoerk in a later paper (Stoerk, 1946). 


\section{EXPERIMENT I}

The object of Exp. I was to test the effects on growth, reproduction and lactation of increasing the amounts of vitamin $B_{1}$ and chalk in a diet already known to induce pyridoxin deficiency by its excessive amounts of these constituents.

\section{Methods}

The basal diet had the following percentage composition: white flour of approx. $70 \%$ extraction $61 \cdot 3$, casein (lactic, unextracted) $24 \cdot 0$, dried brewer's yeast $\mathrm{I} \cdot 9$, vitaminized margarine $10 \cdot 8$, and McCollum's salt mixture no. 185 with ferric citrate $2 \cdot 0$. Vitamins $\mathrm{A}, \mathrm{D}$ and $\mathrm{E}$ were supplied by dissolving $\mathrm{I} \mathrm{g}$. $\alpha$-tocopherol acetate in $50 \mathrm{ml}$. radiostoleum (British Drug Houses Ltd.) and incorporating this solution in the margarine in the proportion of $\mathrm{I} \mathrm{ml}$. to $9 \circ \mathrm{g}$. The diet, to which were added, per $100 \mathrm{~g}$., $0.370 \mathrm{mg}$. $\mathrm{KI}$ and $3.70 \mathrm{mg}$. $\mathrm{MnSO}_{4} \cdot 4 \mathrm{H}_{2} \mathrm{O}$, was given as a stiff paste, the requisite amounts of $\mathrm{KI}, \mathrm{MnSO}_{4}$ and vitamin $\mathrm{B}_{1}$ being added to the water used in making up the daily ration. From mating onwards the animals received in addition $20 \mathrm{ml}$. milk/head daily.

The amounts of vitamin $B_{1}$ and calcium used in group VI of the original experiments (Richards, 1945) were taken as the base and were increased separately or together, so that the present experiment included three further groups, VII, VIII and IX, the supplements of vitamin $B_{1}$ and calcium carbonate being:

\begin{tabular}{lcccc} 
& \multicolumn{4}{c}{ Amount of supplement/100 g. basal diet in group } \\
Supplement & VI $_{\text {VI }}$ & VII & VIII & IX \\
Vitamin B (mg.) & 5.15 & 10.30 & 5.15 & 10.30 \\
Calcium carbonate (g.) & 0.54 & 0.54 & 1.62 & 1.62
\end{tabular}

In the original experiment it was calculated that the additions in group VI gave intakes/Cal. of $1 \mathrm{I} \cdot 3 \mu \mathrm{g}$. vitamin $\mathrm{B}_{1}$ and $0.8 \mathrm{I} \mathrm{mg}$. calcium.

Each of the four groups contained six female and six or seven male rats, litter-mates being distributed throughout the groups. The rats were given the experimental diets from weaning at 23 days of age, and the growth test, with food to appetite, was continued for Io weeks, after which the animals were mated. The experiment was not originally planned as a breeding test, and the number of does in each group was considered too small to form two sections, with and without a pyridoxin supplement, as in the earlier work (Richards, I945). It was therefore planned that each rat should have two matings before receiving pyridoxin, and then be mated once with the pyridoxin supplement. This procedure had to be modified in certain cases according to the experimental results. Litters larger than eight were always reduced to eight 2 days after birth (i.e. at birth +2 days). On the same day litters smaller than eight were made up to eight if suitable young were available for adoption. Thymus weights were determined for weanlings of the second and subsequent litters of each doe. 
Growth performance

\section{Results}

The average weight increases for the Ist week after weaning ( 23 days) and for three subsequent periods of 3 weeks each are shown in Table 1 . In females growth was most rapid in the period from 2 to 4 weeks after weaning, with a considerable decrease in the period from 5 to 7 weeks, and a sharp drop in that from 8 to ro weeks. In males

Table I. Average weight increase for periods up to to weeks of weanling rats receiving a diet low in all $B$-vitamins except vitamin $B_{1}$ to which was added more vitamin $B_{1}$, more calcium or both

\begin{tabular}{|c|c|c|c|c|c|c|c|c|c|}
\hline \multirow[b]{3}{*}{ roup } & \multirow{3}{*}{$\begin{array}{l}\text { No. } \\
\text { of } \\
\text { rats }\end{array}$} & \multirow{2}{*}{\multicolumn{2}{|c|}{$\begin{array}{c}\text { Supplements/100 } \mathrm{g} . \\
\text { basal diet }\end{array}$}} & \multicolumn{4}{|c|}{ Total weight increase/rat for } & \multirow{2}{*}{\multicolumn{2}{|c|}{$\begin{array}{l}\text { Weight increase in } \\
\text { weeks } 2 \rightarrow 7\end{array}$}} \\
\hline & & & & \multirow{2}{*}{$\begin{array}{c}\text { Week } \\
\text { I } \\
\text { (g.) }\end{array}$} & \multirow{2}{*}{$\begin{array}{c}\text { Weeks } \\
2-4 \\
\text { (g.) }\end{array}$} & \multirow{2}{*}{$\begin{array}{c}\text { Weeks } \\
5^{-7} \\
\text { (g.) }\end{array}$} & \multirow{2}{*}{$\begin{array}{c}\text { Weeks } \\
8-10 \\
(\mathrm{~g} .)\end{array}$} & & \\
\hline & & $\underset{\text { (mg.) }}{\text { Vitamin }} \mathrm{B}_{1}$ & $\begin{array}{l}\mathrm{CaCO}_{8} \\
\text { (g.) }\end{array}$ & & & & & $\begin{array}{l}\text { Total } \\
\text { (g.) }\end{array}$ & $\begin{array}{l}\text { Weekly } \\
\text { (g.) }\end{array}$ \\
\hline & & & & & Males & & & & \\
\hline VI & 6 & $5 \cdot 15$ & 0.54 & 15.8 & $79 \cdot 9$ & $90 \cdot 3$ & $56 \cdot 3$ & 170.2 & $28 \cdot 4$ \\
\hline VII & 7 & 10.30 & 0.54 & 14.5 & 86.5 & $83 \cdot 0$ & 64.0 & 169.5 & $28 \cdot 3$ \\
\hline VIII & 7 & $5 \cdot 15$ & 1.62 & $13 \cdot 3$ & 70.0 & $8 I \cdot 3$ & $58 \cdot 1$ & $151 \cdot 3$ & $25 \cdot 2$ \\
\hline IX & 7 & 10.30 & $I \cdot 62$ & $12 \cdot 5$ & $72 \cdot I$ & $76 \cdot 4$ & $59 \cdot 8$ & $148 \cdot 5$ & $24 \cdot 8$ \\
\hline & & & & & Females & & & & \\
\hline VI & 6 & $5 \cdot 15$ & 0.54 & $14 \cdot 1$ & $66 \cdot 2$ & $50 \cdot 5$ & $30 \cdot 4$ & $116 \cdot 7$ & 19.5 \\
\hline VII & 6 & 10.30 & 0.54 & $16 \cdot 2$ & $68 \cdot 2$ & $48 \cdot 3$ & $29 \cdot 0$ & 116.5 & 19.4 \\
\hline VIII & 6 & $5 \cdot 15$ & 1.62 & 13.9 & $6 r \cdot 8$ & 45.7 & $26 \cdot 9$ & 107.5 & 17.9 \\
\hline IX & 6 & 10.30 & $1 \cdot 62$ & 14.6 & $66 \cdot 5$ & 40.8 & $25 \cdot 5$ & $107 \cdot 3$ & $17 \cdot 9$ \\
\hline
\end{tabular}

growth was most rapid in the period from 2 to 7 weeks after weaning, with a decline in that from 8 to ro weeks. The period from 2 to 7 weeks is therefore taken for comparison of the growth rates in the different groups. Comparison of group VI with group VII, and of group VIII with group IX, shows that doubling the supplement of vitamin $B_{1}$ had no effect on the growth rate of males or females. Comparison of group VI with group VIII, and of group VII with group IX, however, shows that the increased calcium supplement retarded the growth rate. If the figures for males and females are taken together, the animals on the increased calcium supplement weighed on an average $128.65 \mathrm{~g}$. compared with $143.25 \mathrm{~g}$. for the animals on the lower calcium intake. The difference of the means $(14.60 \pm 5.50)$ is statistically significant. The calcium was given in the form of carbonate (chalk), and it is not known whether the same amount of calcium in another form would have had the same effect in retarding growth. In the earlier experiments in which chalk was added to raise the calcium intake from 0.15 to $0.36 \mathrm{~g} . / 100 \mathrm{~g}$. diet, the group with chalk showed a higher weight increase at each level of vitamin $B_{1}$ intake than the corresponding group without chalk. The increased supplement of chalk in the present experiment brought the calcium intake approximately to $0.79 \mathrm{~g}$. $/ 100 \mathrm{~g}$. diet, and it would appear that this amount goes beyond that at which addition of chalk to a diet with a considerable proportion of white flour has a beneficial effect on the rate of growth. No differences in general condition were apparent in the animals of different groups at this stage of the experiment. 


\section{Breeding performance}

With the technique adopted of giving each rat two matings before receiving pyridoxin, the animals were $5 \frac{1}{2}-6$ months old before any of them received this supplement, and it soon became evident that the long-continued ingestion of the unbalanced diets had caused irreparable damage to some of them. The number of stillbirths increased

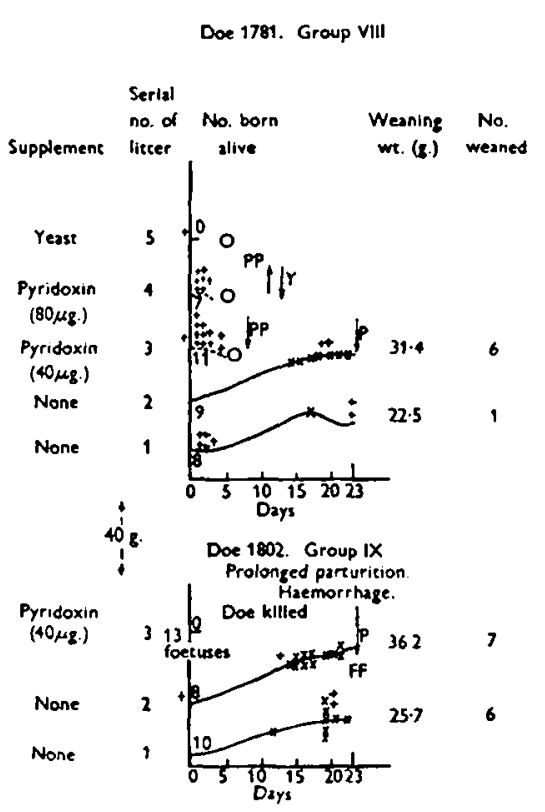

Fig. 1. Breeding capacity of two does irreparably injured by prolonged ingestion of unbalanced diets. Graphs show average weight in $\mathrm{g} / \mathrm{rat}$ from birth to weaning (or death) for individual litters (daily weighings). $x$ denotes fits in sucklings, each $\times$ representing one observed fit. $F$ denotes fits in doe. + denotes death of a suckling, or a stillbirth if placed to left of axis. $\downarrow \mathrm{P}$ indicates commencement of pyridoxin dosing of doe with $40 \mu \mathrm{g}$. daily. \PP indicates commencement of pyridoxin dosing of doe with $80 \mu \mathrm{g}$. daily. $\uparrow \mathbf{P}$ and $\uparrow P P$ indicate withdrawal of pyridoxin. $\mid \mathrm{Y}$ indicates introduction of yeast supplement, increasing yeast content of diet to $14 \%$.

- Litters larger than eight were always reduced to eight 2 days after birth. On the same day litters smaller than eight were made up to eight if suitable young were available for adoption. greatly, and seven of the twenty-four does in the various groups, three of them in group IX, failed to rear any young even when given 40 or $80 \mu \mathrm{g}$. pyridoxin daily or a large supplement of yeast, sufficient to raise the percentage in the diet from I.9 to about 14 . Two of these does bore no live young, even on the pyridoxinsupplemented diets. Any young born alive to the other five does died within 2 or 3 days. A few does, after rearing one or two litters, failed in subsequent matings, even when given supplements of pyridoxin or yeast, as shown in Fig. 1 . With some females, which had apparently suffered less severely, it was possible, by administering and withholding pyridoxin in successive matings, to get apparently normal litters alternating with litters which showed the fits characteristic of pyridoxin deficiency. Examples of these are shown in Fig. 2.

\section{Occurrence of fits in adult rats}

The irreparable damage from prolonged feeding of the unbalanced diets, shown by the reproductive failures described above, was manifested also in the occurrence of fits in several of the adult rats, both male and female. These fits, which were generally very violent, could not be cured by subsequent administration of pyridoxin. They tended to increase in frequency and severity until the animal had to be killed. With one exception, no female succeeded in rearing a litter if she had been seen to have fits before or just after parturition. The one exception was doe 1780 in group VII, fits being observed once 5 days before parturition while pyridoxin was being given. This doe succeeded in rearing a litter of seven to weaning, with no sign of fits in the young, although she herself had fits twice during the suckling period. She was thus able to pass on the pyridoxin to the sucklings, while suffering from some incurable lesion herself, but she 
failed to rear any further litters, whether without pyridoxin, with a double dose of it, or with extra yeast, although she gave birth to three litters which survived a few days. The reproductive record of this rat is shown in Fig. 3. Comparison of the reproductive performances of the different groups showed that the record of group IX, which received the highest amounts of vitamin $B_{1}$ and calcium, was the most unsatisfactory. Only fifty-six young were reared to weaning from repeated matings of six does, with or

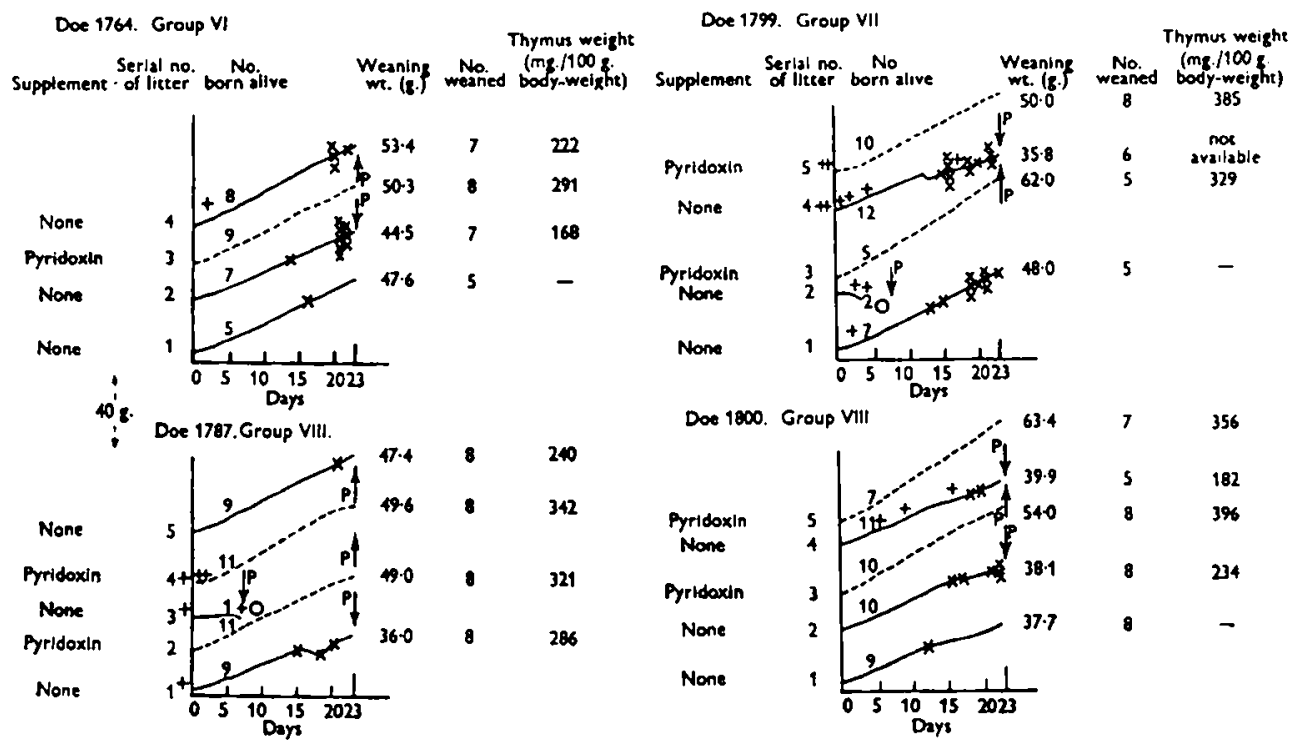

Fig. 2. Breeding capacity of four does impaired but not irreparably injured by prolonged ingestion of unbalanced diets. Weight of thymus and incidence of fits in successive litters bred with and without pyridoxin. Graphs show average weight in g./rat from birth to weaning (or death) for individual litters (daily weighings). $x$ denotes fits in sucklings, each $\times$ representing one observed fit. + denotes death of a suckling, or a stillbirth if placed to left of axis. $\downarrow P$ indicates commencement of pyridoxin dosing of doe with $40 \mu \mathrm{g}$. daily. $\uparrow \mathrm{P}$ indicates withdrawal of pyridoxin. - - litters without pyridoxin. - - - -, litters with pyridoxin.

- See footnote to Fig. I.

without supplements, whereas in groups VI, VII and VIII the numbers reared were ninety-seven, ninety-six and ninety-seven, respectively. Three of the complete failures were in group IX, including one doe which died at the birth of her fourth litter. Another doe (no. I 802, Fig. I), which had a prolonged parturition with severe haemorrhage at the birth of her third litter, and was unlikely to survive, was killed. Difficult parturition in rats is most unusual and its occurrence seems likely to be connected with the imbalance of the diets.

The previous experiments (Richards, 1945) showed that the conditioned pyridoxin deficiency was most severe in the group receiving the highest amount of vitamin $B_{1}$ with extra calcium. In the present experiments the worst results were again obtained in the group receiving the highest amounts of vitamin $B_{1}$ and of calcium. Observations from unpublished experiments, in which various different sources of calcium were compared, indicated that the high vitamin $B_{1}$ intake rather than the increased calcium intake was mainly responsible for inducing the pyridoxin deficiency. In these un- 
published experiments with supplements of vitamin $B_{1}$ and calcium at the level of those for group VI, i.e. $5.15 \mathrm{mg}$. vitamin $B_{1}$ and calcium equivalent to $0.54 \mathrm{~g}$. calcium carbonate/ $100 \mathrm{~g}$. diet, the litters suffered severe fits whether the calcium was given in the form of carbonate, lactate or phosphate. With a low vitamin $B_{1}$ supplement of $0.27 \mathrm{mg}$. $/ \mathrm{ro0} \mathrm{g}$. diet, and a calcium intake at four different levels from 0.15 to $0.79 \mathrm{~g} .1$ $100 \mathrm{~g}$. diet, the extra calcium being given as carbonate, there was no obvious connexion between the amount of calcium in the diet and the occasional fits which occurred

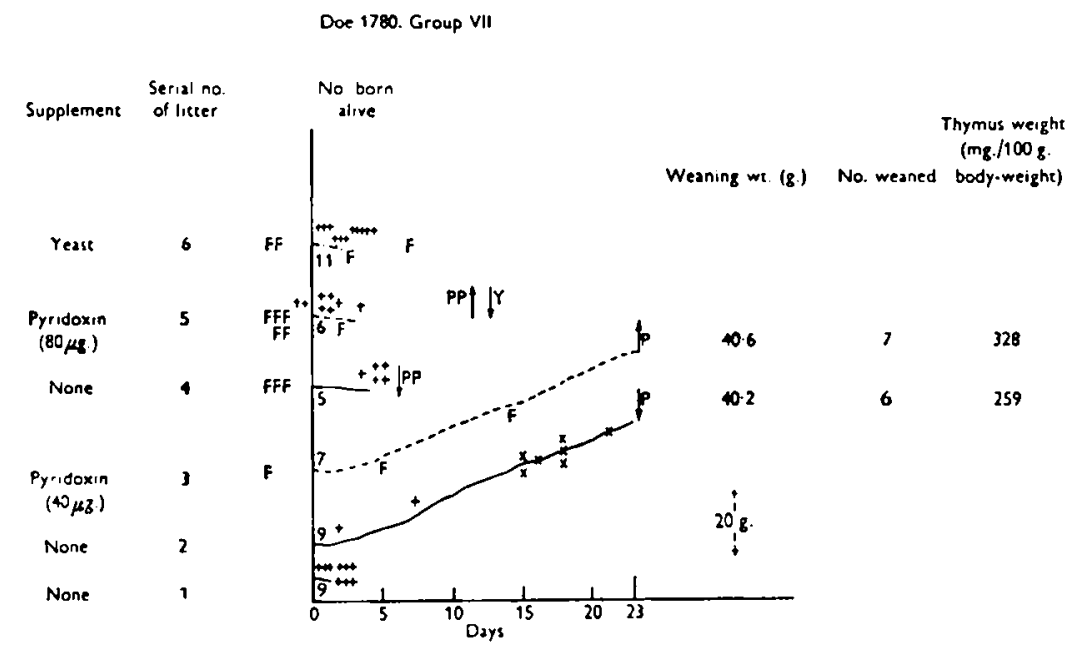

Fig. 3. Breeding record of doe 1780 , group VII. Supplement per $100 \mathrm{~g}$. basal diet of $10 \cdot 30 \mathrm{mg}$. vitamin $\mathrm{B}_{1}$ and of $0.54 \mathrm{~g} . \mathrm{CaCO}_{3}$. This doe was the only one to rear a litter, her third, while showing fits herself. Three subsequent litters died within a few days of birth. Graphs show average weight in g./rat from birth to weaning (or death) for successive litters (daily weighings). $x$ denotes fits in sucklings, each $\times$ representing one observed fit. $F$ denotes fits in doe. + denotes death of a suckling, or a stillbirth if placed to left of axis. $\downarrow P$ indicates commencement of pyridoxin dosing of doe with $40 \mu \mathrm{g}$. daily. $\downarrow \mathrm{PP}$ indicates dosing of doe with $80 \mu \mathrm{g}$. pyridoxin daily. $\uparrow \mathrm{P}$ and $\uparrow \mathrm{PP}$ indicate withdrawal of pyridoxin. $\downarrow \mathrm{Y}$ indicates addition of yeast supplement, increasing yeast content of diet to $14 \%$. - , litters without pyridoxin. - - - -, litters with pyridoxin.

- See footnote to Fig. 1 .

throughout the groups. An attempt to explain why the addition of calcium accentuated the pyridoxin deficiency conditioned by excess of vitamin $B_{1}$ would be premature at this stage.

\section{Weight of the thymus gland in weanling rats}

The investigation of the weight of the thymus gland, suggested by the work of Stoerk \& Zucker (1944), was not begun in time to obtain data from the first litters of does without pyridoxin, and some of them failed to rear a second litter without this supplement. Sufficient evidence was obtained, however, to show that both absolutely, and relatively to body-weight, the thymus weights of weanlings suffering from the conditioned pyridoxin deficiency were much below those attained when the doe had been given pyridoxin during lactation. This is well seen from Fig. 2, where the average thymus weights are shown to the right of the graphs representing the growth of the 
litters. For doe 1800 the thymus weights, in $\mathrm{mg} . / 100 \mathrm{~g}$. body-weight, for successive litters alternately without and with pyridoxin were: without 234 , with 396 ; without 182 , with 356 . The weaning weights of the litters without pyridoxin were much lower than the weights of those with the vitamin, and it might be argued that the low thymus weight was due to nothing more than general malnutrition, but the graphs for the litters of does 1764 and 1787 (Fig. 2) show that thymus atrophy is a feature even of well-grown litters deficient in pyridoxin. Thus, in litter 4 without pyridoxin of doe I764, the weaning weight of $53 \mathrm{~g}$. was actually higher than that of litter 3 with pyridoxin, but the thymus weight, in $\mathrm{mg}$./100 g. body-weight, was only 222 compared with 291. Similarly, with doe 1787 , the thymus weight per $100 \mathrm{~g}$. body-weight of $240 \mathrm{mg}$. for litter 5 without pyridoxin was much below that of $342 \mathrm{mg}$. for litter 4 with pyridoxin, although the difference in weaning weights was only $2 \mathrm{~g}$.

In Table 2 the values for the thymus glands of males and females are given separately, as there seemed to be a tendency for the females to give higher values than the males. The results are expressed as weight of thymus gland in $\mathrm{mg} . / 100 \mathrm{~g}$. body-weight, the live weight of the weanling being taken as body-weight.

Further material for the investigation of thymus weight was obtained from the unpublished experiment referred to above, in which a high supplement of vitamin $B_{1}$ was given with extra calcium in different forms. The animals, which were stock adults given the experimental diets from 10 to 14 days before mating, had two or three matings without pyridoxin, followed by a mating on the pyridoxin-supplemented diet. Fig. 4, which gives graphs for the successive litters of some of these rats, shows again how thymus weight was increased when pyridoxin was given. Although in all cases there was a considerable increase also in weaning weight with pyridoxin dosing, the litters without it were by no means poorly developed. Weaning weights of $4 \mathrm{I}-46 \mathrm{~g}$., which may be considered normal, were associated with relative thymus weights ranging from 124 to $205 \mathrm{mg}$., whereas the values for the litters when pyridoxin was given ranged from 309 to $346 \mathrm{mg}$. In Table 3 the weights of the thymus glands are given separately for male and female weanlings, the number of weanlings included in each estimation being shown, together with their average weight.

The data in Tables 2 and 3 bring out clearly the sex difference in the thymus weights of the weanlings. In twenty-six of thirty-three pairs of results in Table 2, and in thirteen of fifteen pairs in Table 3, the thymus weight of the female is greater than that of the male, often much greater. The difference is statistically significant (see footnotes to Tables 2 and 3). From Table 3 it can be seen that the difference is found even in male and female weanlings of almost identical weaning weights.

The results of the investigation of thymus weights in these experiments on conditioned pyridoxin deficiency may be summarized as follows: the average thymus weight per $100 \mathrm{~g}$. body-weight in the deficient animals of various groups, including both females and males, was $214 \mathrm{mg}$. for 188 weanlings from twenty-nine litters; for the experimental groups receiving pyridoxin or an extra yeast supplement, the average thymus weight per Ioo g. body-weight was $344 \mathrm{mg}$. for $\mathrm{I} 24$ weanlings from twentyseven litters. Examination about the same time of eighty-eight stock weanlings from twenty-one litters gave a corresponding figure of $347 \mathrm{mg}$. 
2

9

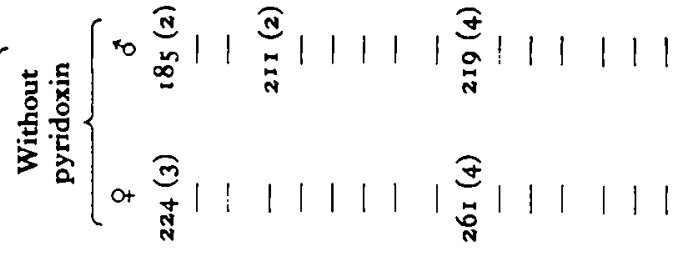
हैำ .

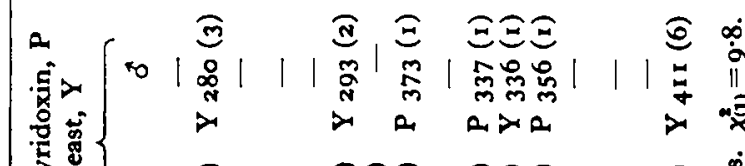
实 . 8 峁| |

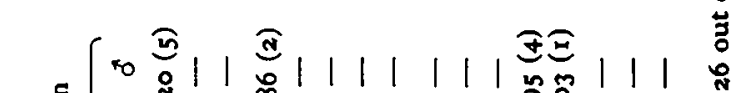

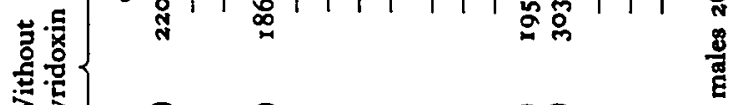

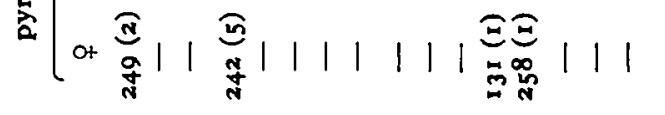

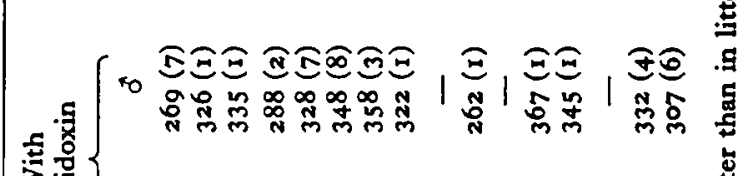

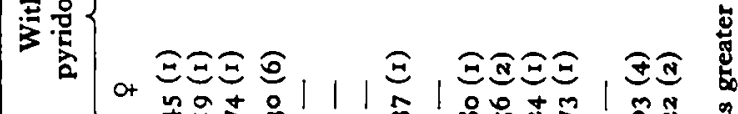
胥胥 र० \& 
Table 3. Mean thymus weights of weanling rats in successive litters from does receiving a diet low in $B$-vitamins except vitamin $B_{1}$ which was present in excess, and containing added calcium from various sources, and with and without added pyridoxin

\begin{tabular}{|c|c|c|c|c|c|c|c|c|c|}
\hline & & & & & & & & Thym & wt. \\
\hline & & & & & $\begin{array}{l}\text { of } \\
\text { ings }\end{array}$ & $\mathrm{We}$ & wt. & & \\
\hline Diet & $\begin{array}{l}\text { Doe } \\
\text { no. }\end{array}$ & Supplement & $\begin{array}{l}\text { Litter } \\
\text { no. }\end{array}$ & 우 & $\delta$ & $\begin{array}{c}9 \\
(g .)\end{array}$ & $\stackrel{d}{(\mathrm{~g} .)}$ & $\begin{array}{l}\text { (mg./ } \\
\text { I00 g.) }\end{array}$ & $\begin{array}{l}\text { (mg./ } \\
100 \mathrm{~g} .)\end{array}$ \\
\hline $\begin{array}{l}\text { High vitamin } \mathrm{B}_{1}+ \\
\text { calcium carbonate }\end{array}$ & 1908 & $\begin{array}{l}\text { None } \\
\text { None } \\
\text { None } \\
\text { Pyridoxin }\end{array}$ & $\begin{array}{l}1 \\
2 \\
3 \\
4\end{array}$ & $\begin{array}{l}3 \\
4 \\
3 \\
3\end{array}$ & $\begin{array}{l}5 \\
4 \\
5 \\
5\end{array}$ & $\begin{array}{l}40 \cdot 2 \\
38 \cdot 5 \\
37 \cdot 3 \\
45 \cdot 7\end{array}$ & $\begin{array}{l}46 \cdot 3 \\
41 \cdot 5 \\
42 \cdot 1 \\
48 \cdot 0\end{array}$ & $\begin{array}{l}257 \\
211 \\
209 \\
316\end{array}$ & $\begin{array}{l}244 \\
159 \\
171 \\
306\end{array}$ \\
\hline $\begin{array}{l}\text { High vitamin } \mathrm{B}_{1}+ \\
\text { calcium carbonate }\end{array}$ & 1856 & $\begin{array}{l}\text { None } \\
\text { None } \\
\text { None } \\
\text { Pyridoxin }\end{array}$ & $\begin{array}{l}1 \\
2 \\
3 \\
4\end{array}$ & $\begin{array}{l}3 \\
4 \\
4 \\
1\end{array}$ & $\begin{array}{l}5 \\
4 \\
4 \\
2\end{array}$ & $\begin{array}{l}40 \cdot 7 \\
38 \cdot 3 \\
39 \cdot 0 \\
70 \cdot 0\end{array}$ & $\begin{array}{l}38 \cdot 6 \\
45 \cdot 3 \\
43 \cdot 8 \\
71 \cdot 5\end{array}$ & $\begin{array}{l}187 \\
132 \\
152 \\
330\end{array}$ & $\begin{array}{l}109 \\
117 \\
138 \\
321\end{array}$ \\
\hline $\begin{array}{l}\text { High vitamin } B_{1}+ \\
\text { calcium phosphate }\end{array}$ & 1907 & $\begin{array}{l}\text { None } \\
\text { None } \\
\text { None } \\
\text { Pyridoxin }\end{array}$ & $\begin{array}{l}1 \\
2 \\
3 \\
4\end{array}$ & $\begin{array}{l}5 \\
4 \\
2 \\
3\end{array}$ & $\begin{array}{l}3 \\
3 \\
2 \\
5\end{array}$ & $\begin{array}{l}47 \cdot 6 \\
41 \cdot 8 \\
43 \cdot 0 \\
51 \cdot 3\end{array}$ & $\begin{array}{l}47 \cdot 5 \\
46 \cdot 0 \\
42 \cdot 8 \\
55 \cdot 4\end{array}$ & $\begin{array}{l}270 \\
242 \\
226 \\
332\end{array}$ & $\begin{array}{l}223 \\
155 \\
173 \\
340\end{array}$ \\
\hline $\begin{array}{l}\text { High vitamin } B_{1}+ \\
\text { calcium lactate }\end{array}$ & 1855 & $\begin{array}{l}\text { None } \\
\text { None } \\
\text { Pyridoxin }\end{array}$ & $\begin{array}{l}1 \\
2 \\
3\end{array}$ & $\begin{array}{l}r \\
4 \\
4\end{array}$ & $\begin{array}{l}7 \\
2 \\
3\end{array}$ & $\begin{array}{l}38 \cdot 5 \\
42 \cdot 3 \\
53 \cdot 3\end{array}$ & $\begin{array}{l}39 \cdot 4 \\
53 \cdot 0 \\
56 \cdot 3\end{array}$ & $\begin{array}{l}217 \\
204 \\
362\end{array}$ & $\begin{array}{l}174 \\
207 \\
325\end{array}$ \\
\hline
\end{tabular}

The mean weight of the thymus in females was greater than in litter-mate males thirteen out of fifteen times. $\chi_{(1)}^{2}=6 \cdot 7$.
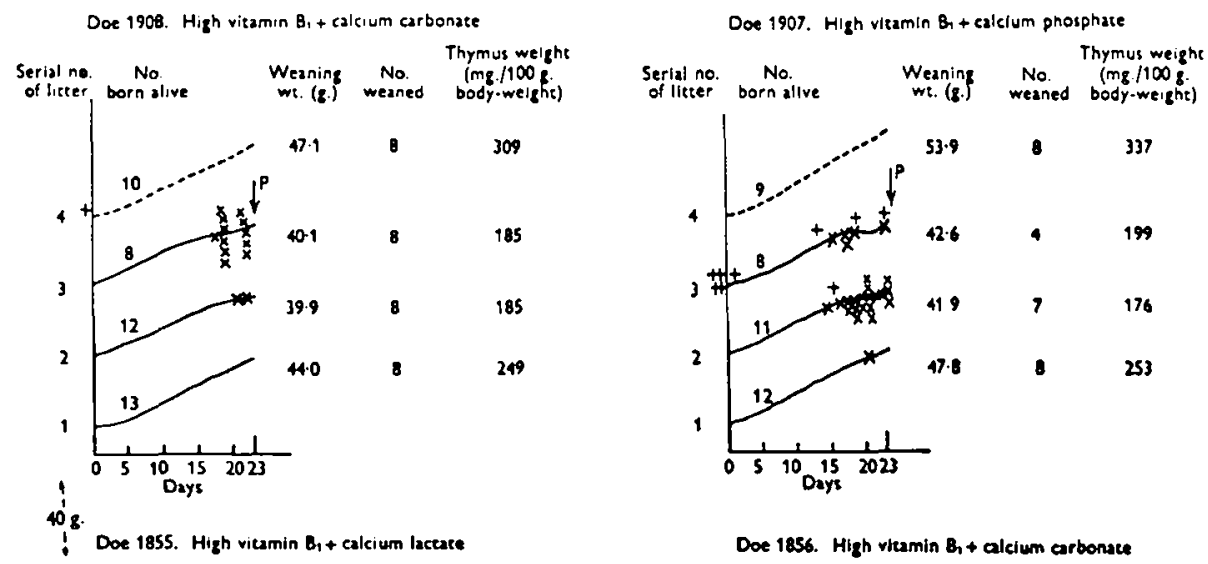

Doe 1856. High vitamin $B_{1}+$ aleium carbonate
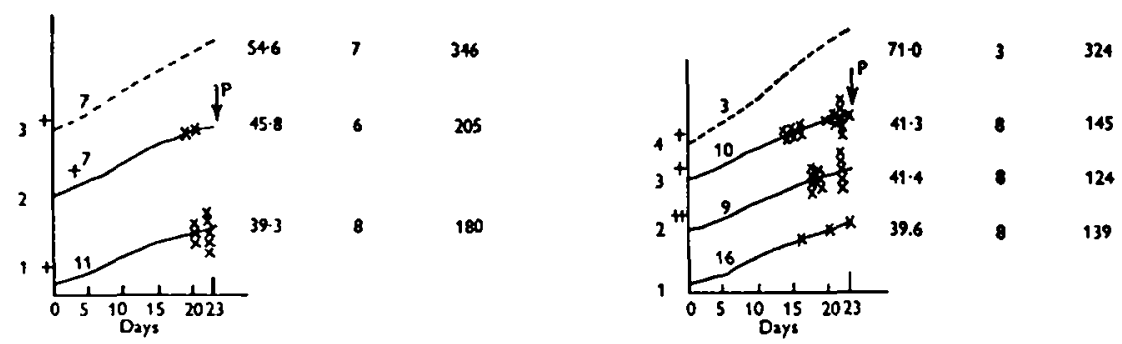

Fig. 4. Increase of mean thymus weight of weanlings when pyridoxin-deficient doe was given pyridoxin. Graphs show average weight per rat from birth to weaning for individual litters (daily weighings).* $x$ denotes fits in sucklings, each $x$ representing one observed fit. + denotes death of a suckling, or a stillbirth if placed to left of axis. $\downarrow P$ indicates commencement of pyridoxin dosing of doe with $40 \mu \mathrm{g}$. daily. —, litters without pyridoxin. - . - - litters $\checkmark$ ith pyridoxin

- See footnote to Fig. $x$. 
That the atrophy of the thymus in these experiments was not due to general mal nutrition is brought out in Table 4, in which the thymus weights for a range of weaning weights from 37 to $54 \mathrm{~g}$. in animals receiving pyridoxin or yeast supplements are compared with the values for deficient animals of the same range of weaning weights. For I 50 animals, representing twenty-two litters reared by does on the pyridoxin-deficient diet, the average value for the average thymus weights of the litters, in $\mathrm{mg} . / 100 \mathrm{~g}$ body-weight, was 201. For II 5 animals, representing twenty litters reared by does receiving pyridoxin or yeast supplements, the corresponding value was 344 .

Table 4. Comparison of the mean thymus weights for litters of weanling rats of the same range of weaning weights, from does given the diet with vitamin $B_{1}$ in excess, with and without added pyridoxin or yeast

\begin{tabular}{|c|c|c|c|c|c|c|c|}
\hline \multicolumn{4}{|c|}{ Without pyridoxin } & \multicolumn{4}{|c|}{ With pyridoxin $(\mathrm{P})$ or yeast $(\mathrm{Y})$} \\
\hline $\begin{array}{l}\text { Doe } \\
\text { no. }\end{array}$ & $\begin{array}{c}\text { No. of } \\
\text { weanlings }\end{array}$ & $\begin{array}{c}\text { Weaning } \\
\text { wt. } \\
\text { (g.) }\end{array}$ & $\begin{array}{l}\text { Thymus wt. } \\
\text { (mg./100 g. } \\
\text { body-wt.) }\end{array}$ & $\begin{array}{l}\text { Doe } \\
\text { no. }\end{array}$ & $\begin{array}{l}\text { No. of } \\
\text { weanlings }\end{array}$ & $\begin{array}{c}\text { Weaning } \\
\text { wt. } \\
\text { (g.) }\end{array}$ & $\begin{array}{l}\text { Thymus wt. } \\
\text { (mg./100 g. } \\
\text { body-wt.) }\end{array}$ \\
\hline 1771 & 6 & $37 \cdot 2$ & 246 & $1771 \mathrm{P}$ & 8 & $36 \cdot 9$ & 3 II \\
\hline 1800 & 8 & $38 \cdot 1$ & 234 & $1771 \mathrm{Y}$ & 8 & 40.4 & 423 \\
\hline 1786 & 8 & $39 \cdot 1$ & 244 & $1780 \mathrm{P}$ & 7 & $40 \cdot 6$ & 328 \\
\hline 1855 & 8 & $39 \cdot 3$ & 180 & $I_{76} \mathrm{P}$ & 2 & $43 \cdot 5$ & 323 \\
\hline 1759 & $\mathbf{I}$ & $39 \cdot 5$ & 172 & I $759 \mathrm{P}$ & 8 & $46 \cdot 2$ & 348 \\
\hline 1856 & 8 & $39 \cdot 6$ & 139 & $1786 \mathrm{P}$ & 8 & $46 \cdot 4$ & 367 \\
\hline 1908 & 8 & $39 \cdot 9$ & 185 & $1908 \mathrm{P}$ & 8 & $47 \cdot 1$ & 309 \\
\hline 1800 & 5 & $39 \cdot 9$ & 182 & $1787 \mathrm{P}$ & 2 & $47 \cdot 3$ & 321 \\
\hline 1908 & 8 & $40 \cdot 1$ & 185 & $1763 \mathrm{Y}$ & 8 & $48 \cdot 3$ & 317 \\
\hline 1856 & 8 & $4 I \cdot 3$ & 145 & I $787 \mathrm{P}$ & 2 & $48 \cdot 5$ & 342 \\
\hline 1856 & 8 & $41 \cdot 4$ & 124 & I $743 \mathrm{P}$ & I & 49.0 & 377 \\
\hline 1907 & 7 & $41 \cdot 9$ & 176 & $177^{\circ} \mathrm{Y}$ & 2 & $49^{\circ} 0$ & 350 \\
\hline 1907 & 4 & $42 \cdot 6$ & 199 & ${ }_{1913} \mathrm{P}$ & 8 & $49 \cdot 1$ & 310 \\
\hline 1908 & 8 & $44^{\circ} 0$ & 249 & $1765 \mathrm{P}$ & 8 & 50.0 & 319 \\
\hline 1764 & 7 & $44 \cdot 5$ & 168 & ${ }^{8} 8_{3} 8 \mathrm{P}$ & 8 & 50.4 & 349 \\
\hline I 765 & 7 & $45 \cdot 6$ & 221 & $1915 \mathrm{P}$ & 8 & $50 \cdot 6$ & 330 \\
\hline 1855 & 6 & $45 \cdot 8$ & 205 & I799 P & 2 & $51 \cdot 0$ & 385 \\
\hline 1787 & 8 & $47 \cdot 4$ & 240 & $1907 \mathrm{P}$ & 8 & 53.9 & 337 \\
\hline 1907 & 8 & $47 \cdot 8$ & 253 & $1800 \mathrm{P}$ & 2 & 543 & 396 \\
\hline 1744 & 5 & $50 \cdot 8$ & 235 & I $855 \mathrm{P}$ & 7 & $54 \cdot 6$ & 346 \\
\hline 1765 & 7 & $51 \cdot 3$ & 226 & & & & \\
\hline 1764 & 7 & $53 \cdot 4$ & 222 & & & & \\
\hline & tal I $50 \mathrm{M}$ & $\begin{array}{l}\text { In of avera } \\
\text { litters }\end{array}$ & 201 & & tal ins $\mathrm{M}$ & $\begin{array}{l}\text { an of avera } \\
\text { litters }\end{array}$ & 344 \\
\hline
\end{tabular}

\section{Indications of the occurrence of other conditioned deficiencies}

In these experiments on vitamin $B$ imbalance there were indications that deficiencies other than that of pyridoxin might have been induced by the excess of vitamin $B_{1}$. Several animals suffered from body sores which did not correspond to the published descriptions of skin lesions due to uncomplicated pyridoxin deficiency. One doe in particular in Exp. I became such a mass of sores that she could scarcely be handled. Dosing with pyridoxin effected no improvement, and administration of riboflavin for a few days seemed to make matters worse. Finally a large dose of yeast was given daily. Within about a week most of the sores had healed, and the animal's body was covered with a fresh growth of hair. 
The effect of extra yeast on the breeding performance of another rat is worthy of remark also. After rearing one litter without pyridoxin, and one with it, this doe's subsequent record was one of failure even with pyridoxin. Eventually, after 64 days on a high yeast supplement, another litter was born and successfully reared, and it is of interest to note that the highest thymus values, in $\mathrm{mg} . / \mathrm{ro0} \mathrm{g}$. body-weight, recorded in these experiments were those obtained from this litter, $46 \mathrm{r}$ for two females and $4 \mathrm{II}$ for six males. These indications of other deficiencies made good by an ample supply of yeast suggested an attempt to determine the effect, particularly on thymus development, of adding vitamin B-complex factors other than pyridoxin singly to the diet of high vitamin $B_{1}$ content.

\section{EXPERIMENT 2}

The object of Exp. 2 was to test the effect on growth, reproduction, lactation and thymus development of adding various vitamin $B$ factors singly to a diet high in vitamin $B_{1}$ and low in other factors of the vitamin B complex.

\section{Methods}

The basal diet was the same as in Exp. r. For the first breeding test the supplements of vitamin $B_{1}$ and chalk were at the base level of the earlier experiments, i.e. about $5.15 \mathrm{mg}$. vitamin $B_{1}$ and $0.54 \mathrm{~g}$. calcium carbonate/100 g. diet, but in the second breeding test the amount of vitamin $B_{1}$ was halved. The supplements tested, and the amounts given, in mg./rat daily, were: nicotinic acid 0.4 , calcium pantothenate 0.16 , choline $12 \cdot 0$, inositol 0.8 , riboflavin 0.08 , pyridoxin 0.04 , and $p$-aminobenzoic acid 0.8 . Folic acid was unobtainable at the time of the experiment.

The rats were weanlings from stock aged 23 days. There were seven groups corresponding to the above seven supplements, and a negative control group which received no supplement. Each group contained six males and eight or nine females of average initial weights $45 \cdot 7-46 \cdot 8$ and $43 \cdot 4-45^{\circ} 4 \mathrm{~g}$. respectively. The animals in the second breeding test were the same as in the first.

\section{Growth performance}

\section{Results}

The animals were maintained on the diets for 7 weeks before mating, and the average weight increase for the individuals in the groups for each successive week of the test is shown in Table 5, the cumulative weekly increase being shown in Fig. 5.

It is evident that of the supplements tested pyridoxin had the greatest effect in promoting growth in both males and females. The effect was apparent even in the Ist week and, in the males, the high rate of growth was maintained throughout the test, until at the end of the $7_{\text {th }}$ week the average weight increase of the males in the pyridoxin group exceeded that of the males in the other groups by $30 \cdot 0-46 \cdot 2 \mathrm{~g}$./rat. In the females the growth-promoting effect of pyridoxin was most marked up to the end of the $4^{\text {th }}$ week, when the cumulative weight increase of the females in the pyridoxin group exceeded that of the other groups by $12 \cdot 3-19^{\circ} \mathrm{I}$ g. This group did not subsequently increase its lead, the other groups making up part of their weight deficit, but after 
7 weeks the total weight increase for individual females in the pyridoxin group still exceeded that in the other groups by $8 \cdot 9-17.5 \mathrm{~g}$. Weight differences among the other groups were relatively small, and the general superiority of the pyridoxin group is well seen by comparing its weight week by week with that of a composite group formed from the average weights of all the other groups (see Fig. 6).

Table 5. Average weekly weight increase for 7 weeks of groups of young male and female rats given the diet with vitamin $B_{1}$ in excess to which was added a supplement of one of seven individual B-vitamins

\begin{tabular}{|c|c|c|c|c|c|c|c|c|c|c|c|}
\hline \multirow{2}{*}{\multicolumn{2}{|c|}{$\begin{array}{c}\text { No. } \\
\text { Group of } \\
\text { no. rats }\end{array}$}} & \multirow{2}{*}{ Supplement } & \multicolumn{7}{|c|}{ Weight increase in week } & \multicolumn{2}{|c|}{$\begin{array}{l}\text { Weight increase in } \\
\text { weeks } 2-7\end{array}$} \\
\hline & & & $\begin{array}{c}\mathbf{I} \\
\text { (g.) }\end{array}$ & $\stackrel{2}{(g .)}$ & $\begin{array}{c}3 \\
(\mathbf{g})\end{array}$ & $\left(\begin{array}{l}4 \\
(\mathrm{~g} .)\end{array}\right.$ & $\begin{array}{c}5 \\
(\mathrm{~g} .)\end{array}$ & $\begin{array}{c}6 \\
(\mathrm{~g} .)\end{array}$ & $\begin{array}{l}7 \\
\text { (g.) }\end{array}$ & $\begin{array}{l}\text { Total } \\
\text { (g.) }\end{array}$ & $\begin{array}{l}\text { Weekly } \\
\text { (g.) }\end{array}$ \\
\hline \multicolumn{12}{|c|}{ Males } \\
\hline o & 6 & None & 22.5 & $24 \cdot 3$ & $17 \cdot 4$ & 22.9 & $27 \cdot 8$ & $26 \cdot 0$ & $26 \cdot 8$ & $145 \cdot 2$ & $24 \cdot 2$ \\
\hline I & 6 & Nicotinic acid & $21 \cdot 6$ & 25.8 & $2 \pi \cdot 6$ & $23 \cdot 8$ & $28 \cdot 5$ & $27 \cdot 0$ & $26 \cdot 8$ & 153.5 & $25 \cdot 6$ \\
\hline 2 & 6 & Calcium pantothenate & $22 \cdot 0$ & $25 \cdot 3$ & 23.4 & $26 \cdot 2$ & $29 \cdot 3$ & $28 \cdot 0$ & 23.4 & 155.6 & $25 \cdot 9$ \\
\hline 3 & 6 & Choline & $21 \cdot 5$ & $27 \cdot 7$ & $21 \cdot 0$ & 25.4 & $27 \cdot 2$ & $2 \pi \cdot 3$ & $26 \cdot 5$ & $149 \cdot 1$ & $24 \cdot 8$ \\
\hline 4 & 6 & Inositol & $22 \cdot 8$ & $26 \cdot 2$ & $20 \cdot 5$ & 27.4 & $30 \cdot 4$ & $26 \cdot 2$ & 25.9 & $156 \cdot 6$ & $26 \cdot x$ \\
\hline 5 & 6 & Riboflavin & $25 \cdot 5$ & $26 \cdot 5$ & $20 \cdot 6$ & 23.5 & $24 \cdot 7$ & $23 \cdot 6$ & $24 \cdot I$ & 143.0 & 23.8 \\
\hline 6 & 6 & Pyridoxin & $26 \cdot 9$ & $31 \cdot 9$ & $26 \cdot 0$ & $30 \cdot 5$ & $32 \cdot 1$ & $30 \cdot 5$ & $31 \cdot 5$ & $182 \cdot 5$ & $30 \cdot 4$ \\
\hline 7 & 6 & p-Aminobenzoic acid & $22 \cdot 5$ & 245 & $19 \cdot 3$ & $22 \cdot 0$ & $25 \cdot 6$ & $25 \cdot 1$ & $24 \cdot 2$ & 140.7 & 23.5 \\
\hline \multicolumn{12}{|c|}{ Females } \\
\hline ० & 9 & None & $19 \cdot 1$ & $22 \cdot 0$ & 155 & $16 \cdot 0$ & $18 \cdot 4$ & $14 \cdot 1$ & 150 & IOI.O & 16.8 \\
\hline I & 9 & Nicotir & 17.5 & $22 \cdot 8$ & 17.4 & 15.1 & $17 \cdot 0$ & 14.0 & $14 \cdot 6$ & $100 \cdot 9$ & $16 \cdot 8$ \\
\hline 2 & 8 & Calcium pantothenate & $19 \cdot 8$ & $24 \cdot 8$ & $17 \cdot 8$ & $17 \cdot 0$ & $17 \cdot 5$ & $15 \cdot 1$ & $13 \cdot 0$ & $105 \cdot 2$ & $17 \cdot 5$ \\
\hline 3 & 9 & Choline & $19 \cdot 1$ & 23.9 & $16 \cdot 1$ & $16 \cdot 8$ & $18 \cdot 3$ & $14 \cdot 2$ & $14 \cdot 8$ & $104 \cdot 1$ & $17 \cdot 4$ \\
\hline 4 & 9 & Inositol & $18 \cdot 8$ & $21 \cdot 3$ & 16.2 & $17 \cdot 1$ & $17 \cdot 8$ & $13 \cdot 9$ & 13.4 & $99 \cdot 7$ & 16.6 \\
\hline 5 & 9 & Riboflavin & $18 \cdot 4$ & $24 \cdot I$ & $\times 6.5$ & $16 \cdot 4$ & $19 \cdot 4$ & $16 \cdot 1$ & $12 \cdot 4$ & 104.9 & 17.5 \\
\hline 6 & 8 & Pyridoxin & $21 \cdot 9$ & 28.4 & 22.9 & $18 \cdot 5$ & $16 \cdot 4$ & 15.4 & $12 \cdot 4$ & $114 \cdot 0$ & 19.0 \\
\hline 7 & 9 & p-Aminobenzoic acid & $20 \cdot 3$ & 23.4 & $17 \cdot 2$ & $16 \cdot 2$ & $19 \cdot 6$ & 15.4 & $14 \cdot 9$ & $106 \cdot 7$ & $17 \cdot 8$ \\
\hline
\end{tabular}

Growth rate at different times on the unsupplemented basal diet. In this experiment the weekly rate of increase for group o, the negative control group without a vitamin Bfactor supplement, was lower for both males and females than for the corresponding group (group VI) of Exp. I (see Table I). From a review of the experimental conditions, including the possibility of seasonal influences, it seemed probable that the lower growth rates of the present experiment were due to the use of a yeast lower than usual in its content of some or all of the factors of the vitamin B complex. One of the defects of this experimental diet is that the intake of vitamin B factors is not accurately controlled. When the experiments were begun in 1943 it was more convenient, because of the war, to use yeast as a general source of the B-vitamins than to attempt to procure all the necessary synthetic products. The amount of yeast added was intentionally kept low to correspond roughly to the low vitamin $B$ content of the human diet used in the experiments which led up to the present work on vitamin B imbalance. Thus a diminution in the vitamin B content of a particular sample of yeast, such as may have occurred here, might easily reduce the intake of vitamin $B$ factors below the desired borderline level. 


\section{Breeding performance: first breeding test}

Weaning weights. The results of the first breeding test are summarized in the upper half of Table 6, and in Fig. 7 which, in a series of graphs, shows the weights of all the individual litters from birth to weaning at 23 days, and indicates the incidence of fits.
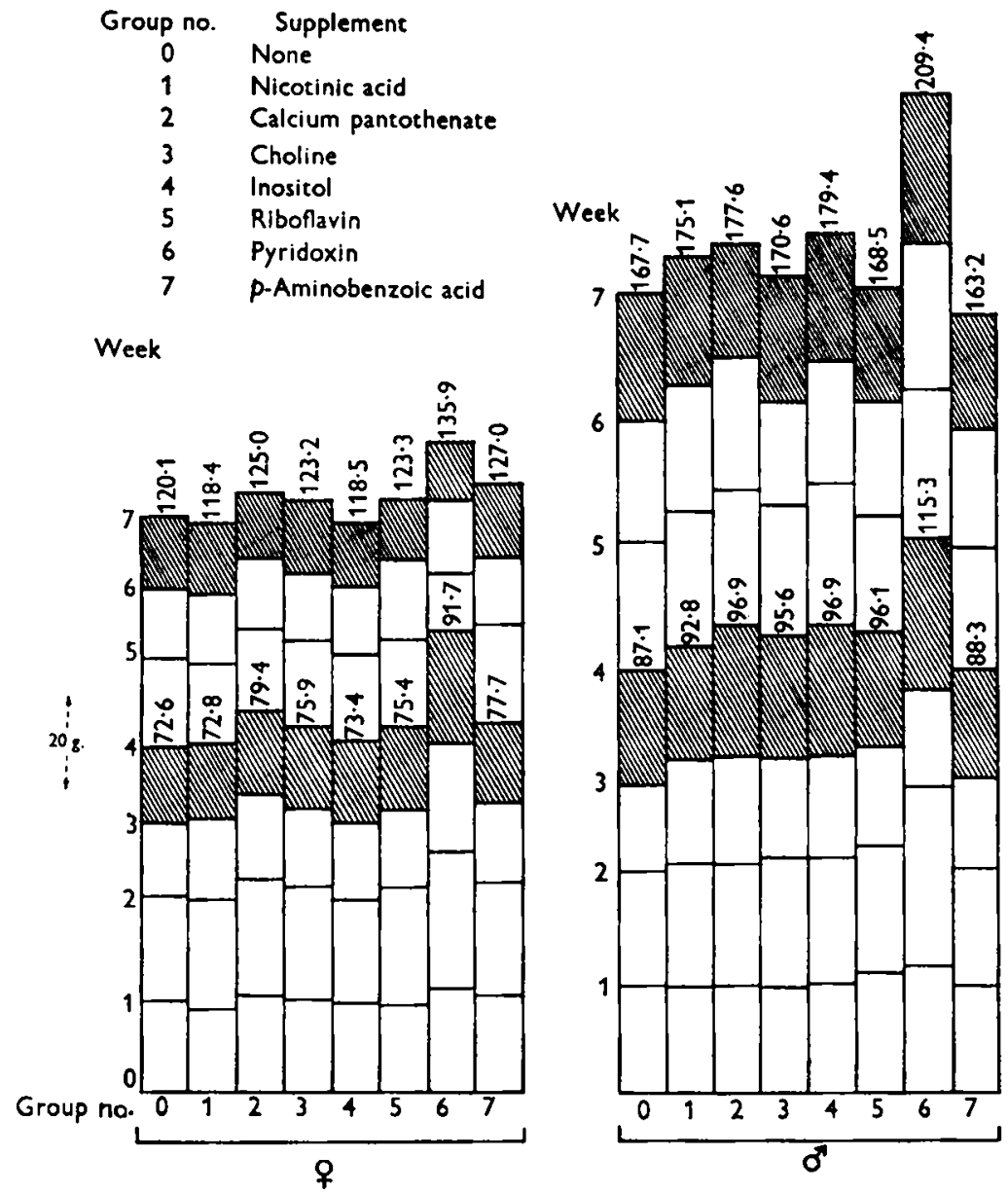

Fig. 5. Cumulative weekly increases in weight (g.) for 7 weeks after weaning, of rats receiving single vitamin $\mathbf{B}$ factors as supplements to a diet high in vitamin $B_{1}$ but low in other B-vitamins. Each block in the vertical columns represents the average weight increase of a group for I week, the total increases for 4 weeks and 7 weeks being given in figures.

Occurrence of fits. The graphs of Fig. 7 show that the effects of the induced pyridoxin deficiency were very severe. Fits were frequent in the litters of all groups except that receiving pyridoxin, in which no fits were seen. The approximate number of fits recorded in the other groups ranged from forty-one to seventy-eight.

Deaths of sucklings: other possible deficiencies. The mortality rate among sucklings from 12 days onwards was very high, but it varied among the groups, suggesting that the deaths were not due entirely to deficiency of pyridoxin. One litter in the pyridoxin 
group itself gives evidence of some other cause of death, for six of the litter died between 16 and 20 days, and the two survivors averaged only $29 \mathrm{~g}$. at weaning.

In the group having the basal diet unsupplemented, apart from one litter of seven rats which was reared to a weight of $38 \cdot 7 \mathrm{~g}$., the record was one of almost total failure. Six entire litters died in the second half of the suckling period, and in the remaining litter only one rat survived to weaning, when it weighed only $25.5 \mathrm{~g}$. 'The riboflavin and calcium-pantothenate groups, like the group on the basal diet alone, had only eight survivors each, and the record of the choline group was even worse, not a single rat of eight litters surviving to weaning. It seemed as if the large dose of choline, chosen from data in the literature, had had some toxic effect. In the groups receiving nicotinic acid

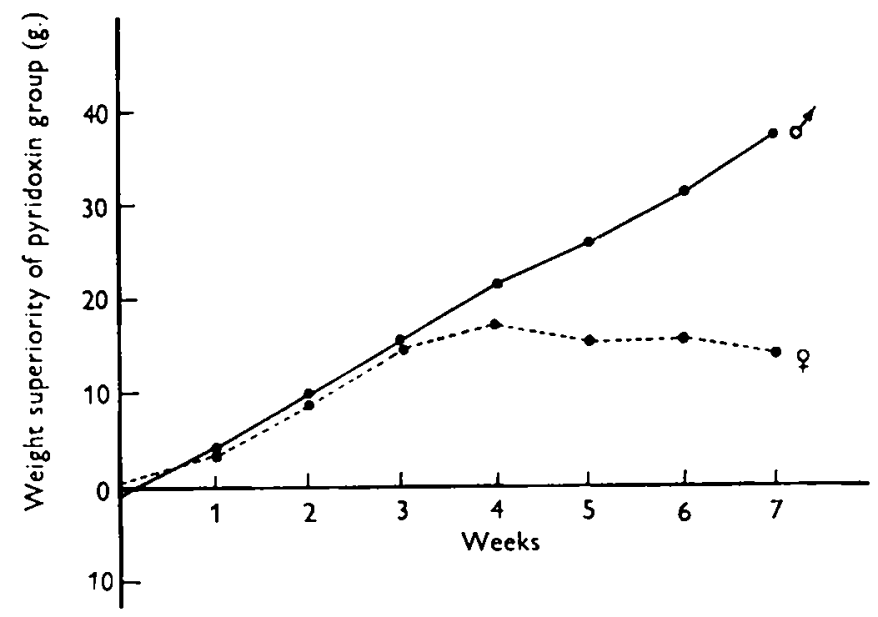

Fig. 6. Rats receiving single vitamin $B$ factors as supplement to a diet unbalanced by excess of vitamin $B_{1}$. Graphs show excess in weight of pyridoxin groups (male and female) over composite group whose weight represents the average weights of the groups receiving other individual vitamin $B$ factors or no supplement.

and inositol the mortality was somewhat less than in the group without any supplement, twenty-three and twenty-four young being reared in these two groups, but the survivors were low in weight, the average in each group being only $28 \mathrm{~g}$. In the $p$-aminobenzoic acid group the number of deaths among the sucklings was still less, although the incidence of fits was high. In this group two litters died shortly after birth, but five of the remaining six litters were successfully reared to weaning, giving a total of thirty-six young reared, with an average weaning weight of $35.2 \mathrm{~g}$. The lower mortality of these groups, however, is not considered statistically significant, because of the small numbers in the groups.

Fig. 7. Weight graphs of litters from does receiving additions of single vitamin $B$ factors to a diet high in vitamin $B_{1}$ but low in other $B$-vitamins. Vitamin $B_{1}$ supplement $5.15 \mathrm{mg} / 100 \mathrm{~g}$. diet. Graphs show average weight in $\mathrm{g}$./rat from birth to weaning (or death) for individual litters (daily weighings).* Ad. above a graph indicates adoption of young. Mean thymus weights in $\mathrm{mg}$./100 g. body-weight for weanlings weighing $30 \mathrm{~g}$. or over are shown to the right of the graph. If thymus value is bracketed, no weanling in the litter reached $30 \mathrm{~g}$. $\times$ denotes fits in sucklings, each $\times$ representing three or fewer observed fits. + denotes death of a suckling, or a stillbirth if placed to left of axis.

- See footnote to Fig. I. 


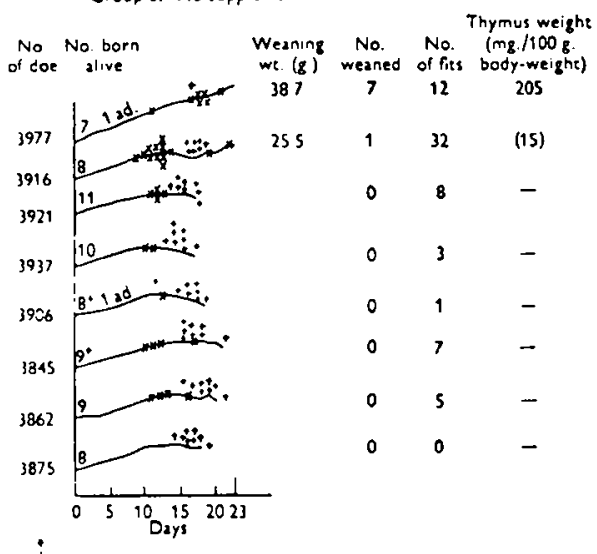

No. No.born Weaning No. No. $(\mathrm{mg} / 100 \mathrm{~g}$. of doe alive wr. (g) weaned of fits body-weight)

$40 \mathrm{~g}$. Group 2. Caleium pantothenate
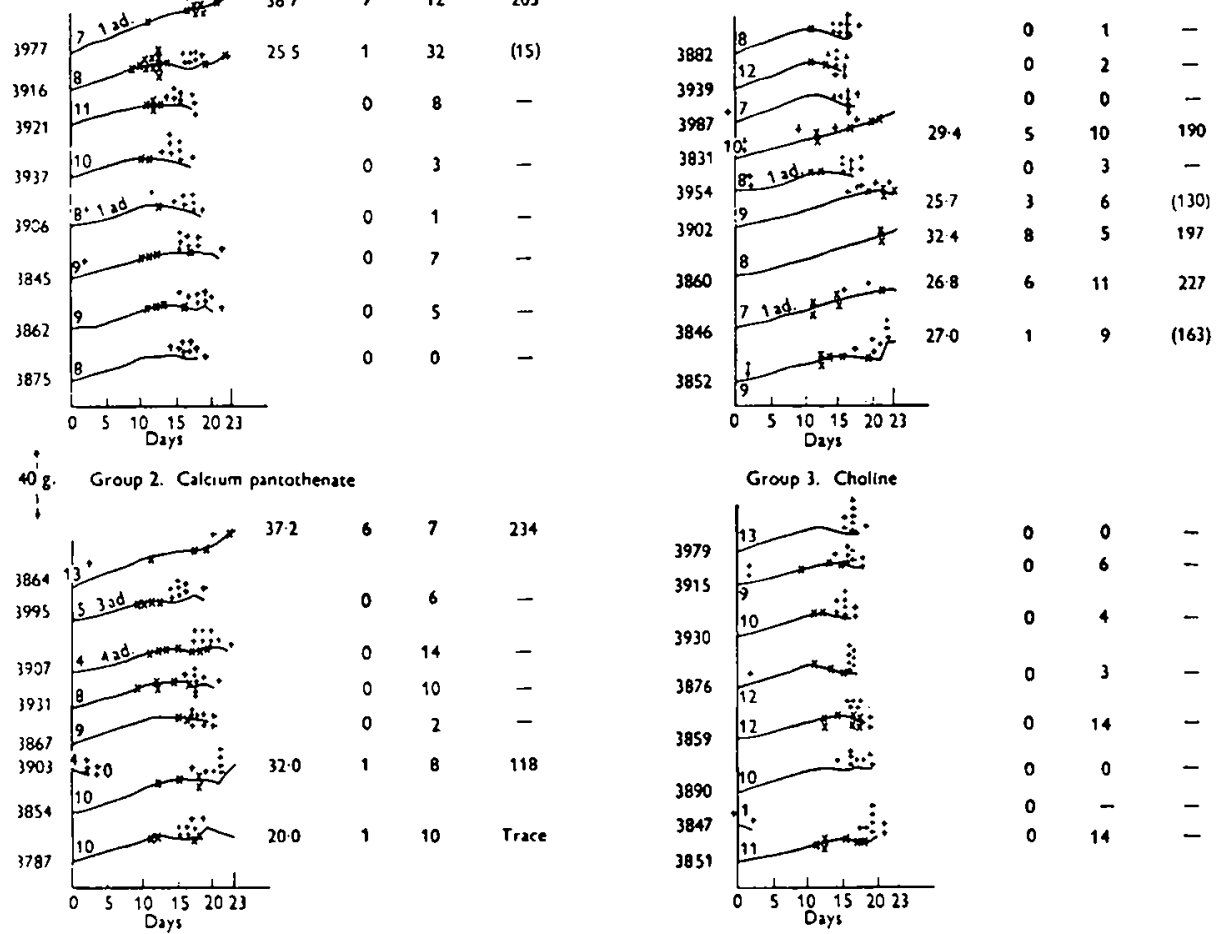

Group 4. Inositol No. No. born $\quad$ Weaning No. No. (mg/weight
of doe alive
wt. (8) weaned of fies body-weight)
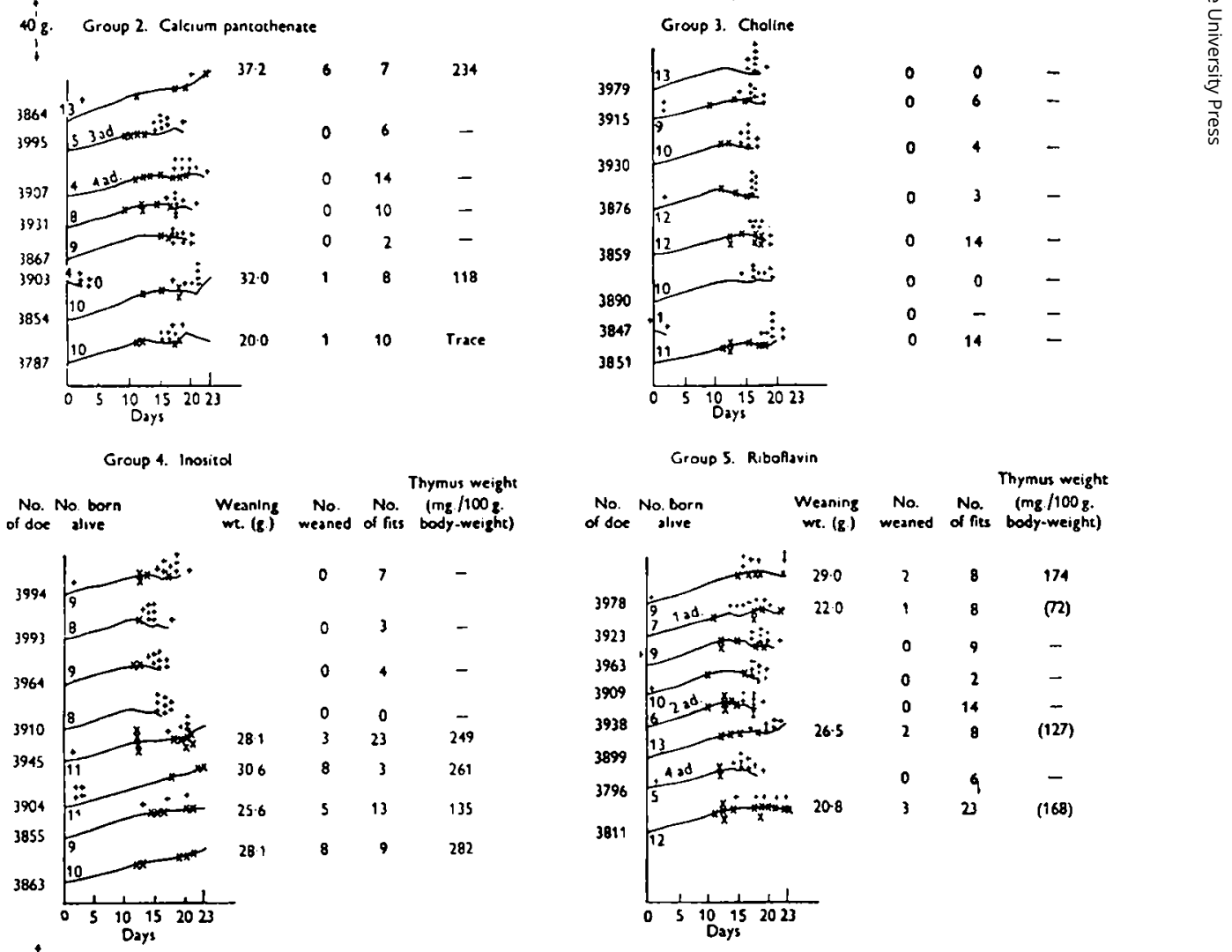

Group 5. Ruboflavin

Thymus weight

No. Weaning No. No. (mg/100 g. of doe alive we. (g.) weaned of fits body-weight)
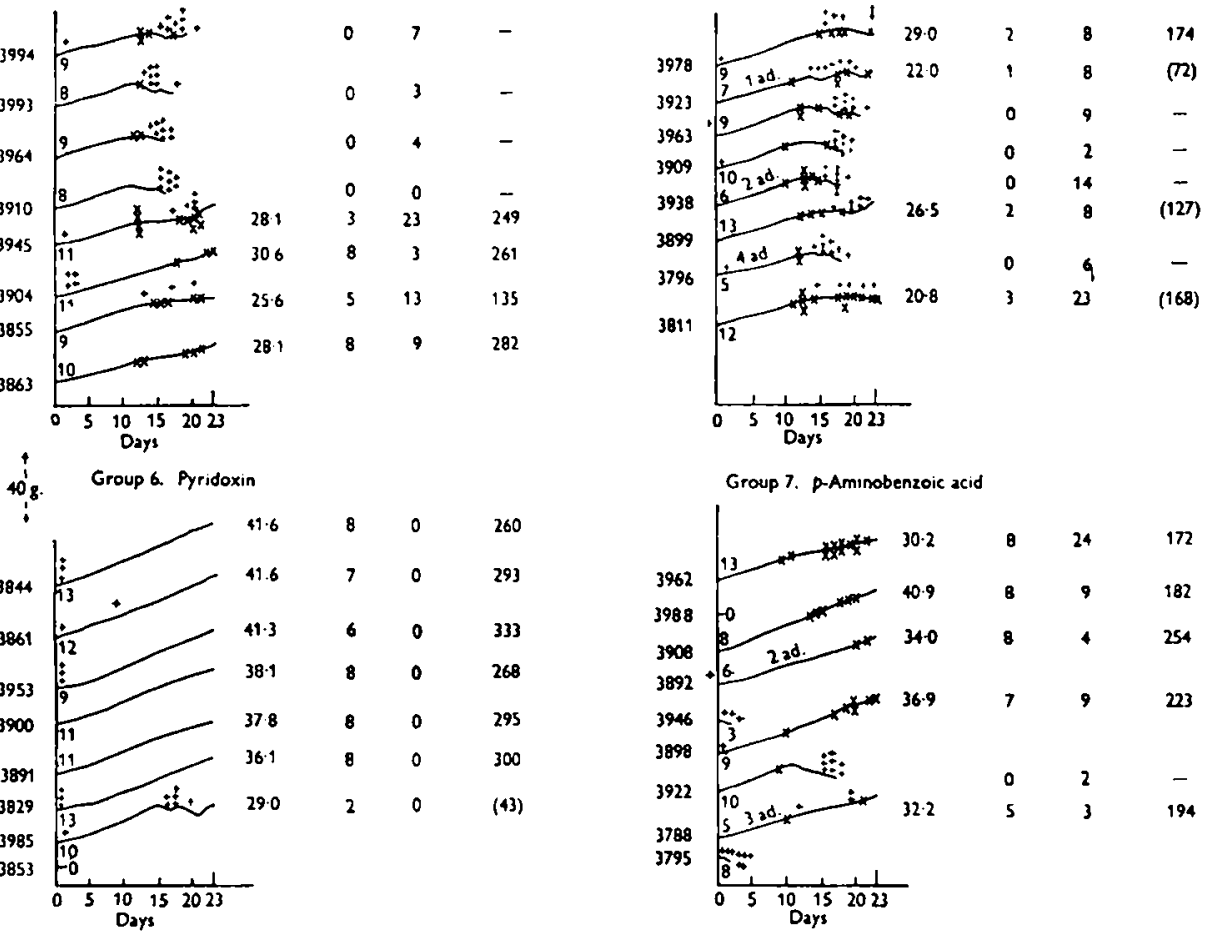

Fig. 7 
Breeding performance in reference to the basal diet. The record of the group having the basal diet unsupplemented was distinctly worse than in other experiments with the same diet and the same intake of vitamin $B_{1}$. This supports the inference drawn from the growth test of the same group that the composition of the diet had changed in some way, most probably by a reduction in the intake of vitamin B-complex factors. So few of the litters reached the weaning stage that this breeding test failed to provide the required data for determining the effect of the single vitamin $B$ factors on the thymus development of the weanlings. It was obvious, therefore, that some modification of the diet was necessary before repeating the test. Instead of making a general increase in the intake of vitamin B-complex factors by increasing the amount of yeast, with the risk of adding too much and masking the effect of the excess of vitamin $B_{1}$, the supplement of this vitamin was halved, so that the imbalance of vitamin $B$ factors was made less drastic.

\section{Breeding performance: second breeding test}

The supplies of foodstuffs used were the same as in the previous test, so that the basal diet was unaltered except for the halving of the supplement of vitamin $B_{1}$. The amounts of the other supplements given remained as before, except that the choline supplement was reduced from $\mathrm{I} 2$ to $8 \mathrm{mg}$./rat daily. The results of the second breeding test are summarized in the lower half of Table 6 and in Fig. 8. Comparison of the data of the two breeding tests shows the remarkable effect of halving the vitamin $B_{1}$ intake on the weaning weights of the young rats, the incidence of fits, and the mortality among the sucklings. Each of these aspects deserves separate consideration.

Weaning weights. Weaning weights were low in the litters with few survivors and in some of the larger litters reared, but the weaning weights in the second test were significantly greater than in the first $(P<0.01$; see Table 6$)$. From the graphs in Fig. 7 it can be seen that in the first test only ten litters reached an average weight of $35 \mathrm{~g}$. or more, six of them in the pyridoxin group. In the second test (Fig. 8), forty-one litters attained this average weaning weight, and in every group, even including the poor litters, the average weight per rat was $35 \mathrm{~g}$. or over.

Occurrence of fits. Fits were frequent and severe in all groups except that receiving pyridoxin. In three groups, those receiving a supplement of nicotinic acid, calcium pantothenate, or choline, there was little or no diminution in the number of fits observed, but the other four groups gave indication of some improvement. The animals were under observation for about $8 \mathrm{hr}$. daily, but the number of fits noted even during this period must be regarded as only approximate. The fits are usually, but not

Fig. 8. Weight graphs of litters from does receiving additions of single vitamin $B$ factors to a diet high in vitamin $B_{1}$ but low in other $B$-vitamins. Vitamin $B_{1}$ supplement $2.58 \mathrm{mg} . / 100 \mathrm{~g}$. diet. Comparison with Fig. 7 shows effect on incidence of fits, survival of young, and weaning weights, of halving the vitamin $B_{1}$ supplement. Graphs show average weight per rat from birth to weaning (or death) for individual litters (daily weighings). Ad. above a graph indicates adoption of young. Mean thymus weights in $\mathrm{mg} . / 100 \mathrm{~g}$. body-weight for weanlings weighing $30 \mathrm{~g}$. or over are shown to the right of the graph. If thymus value is bracketed, no weanling in the litter reached $30 \mathrm{~g} . \times$ denotes fits in sucklings, each $x$ representing three or fewer observed fits. + denotes death of a suckling, or a stillbirth if placed to left of axis.

- See footnote to Fig. 1. 
Group 0. No supplemens

Thymus weight

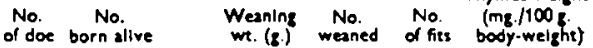
47.0 4 B 2182 3977 (11) 36.0

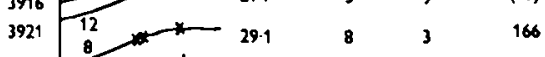

3937 19 $37.6 \quad 5 \quad 5 \quad 197$

3906 19 $19.9 \quad 4 \quad 3 \quad 36$

$3845 x^{4} x^{+2.2} 7227$

$3862{ }_{10}^{11} 228$

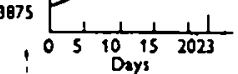

40.8. Group 2. Calclum pantothenate
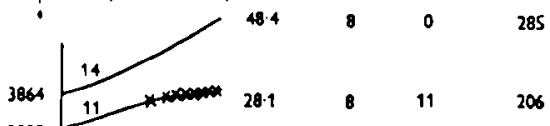

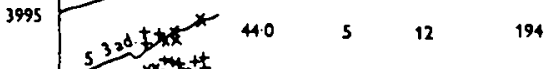

3954 17.5 1 ill

$+7220 \times 340 \quad 3 \quad 10 \quad 221$

$330 \quad 3 \quad 10 \quad 10420$

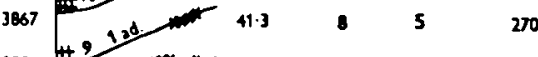

$308054+11+306$

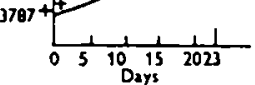

Group 4. Inositol No. No. Weaning No. No Thymus weight
of doe bornalive we ( 8.$)_{\text {weaned of fits. body.weight) }}$

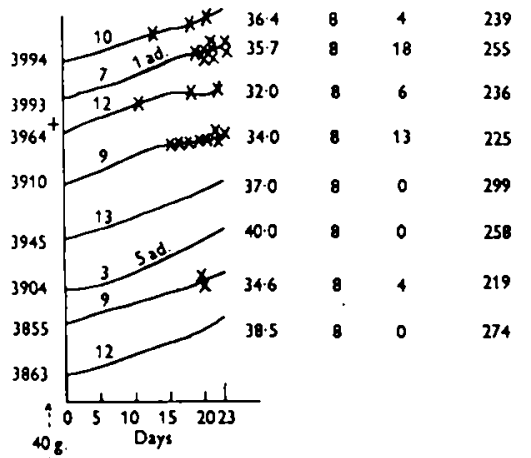

: Group 6. Pyridoxin 43.5 B 00279

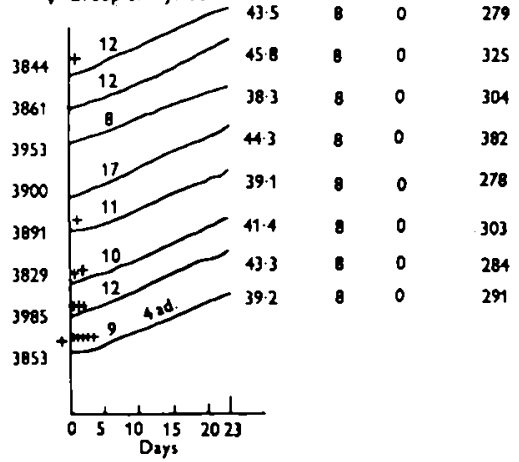

Group 1. Nicotinic acld

No. No Weaning No. No Thymus welghe of doe bornalive we. (s.) weaned of fits body-weight)

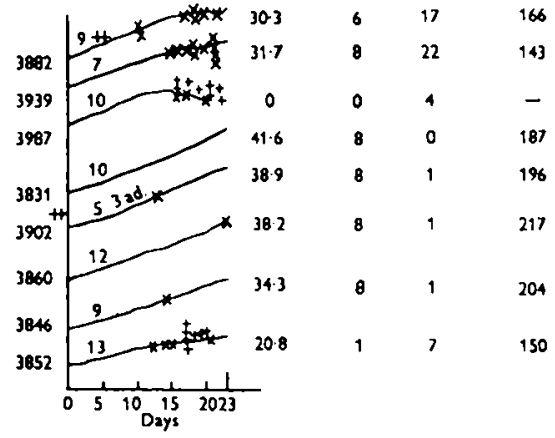

Group 3. Choline

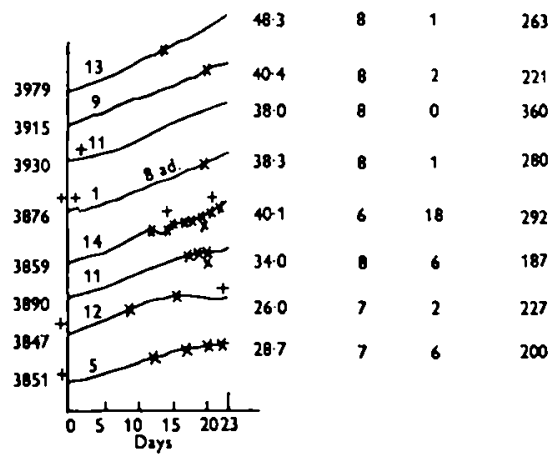

Group S. Riboflavin

No Weaning Ne. No Thymus weight No No. Weaning Ne. No Ne $_{\text {we }} / 1008$
of doe born alive (g) weaned of fits body-weight)

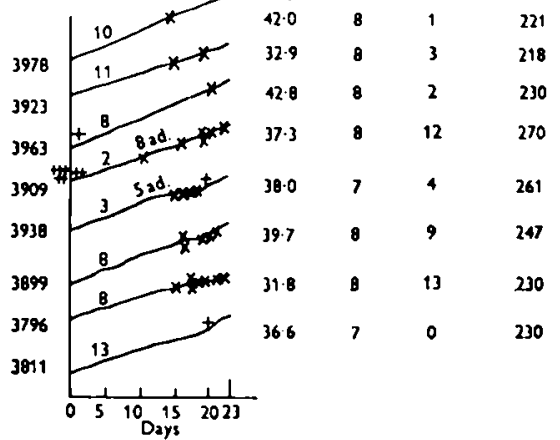

Group 7. p-Aminobenzolc acid

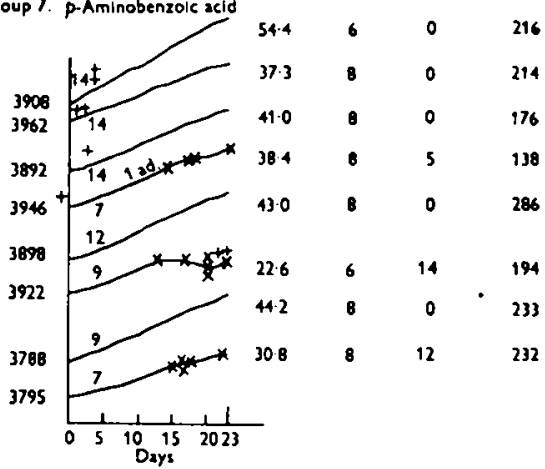

Fig. 8 


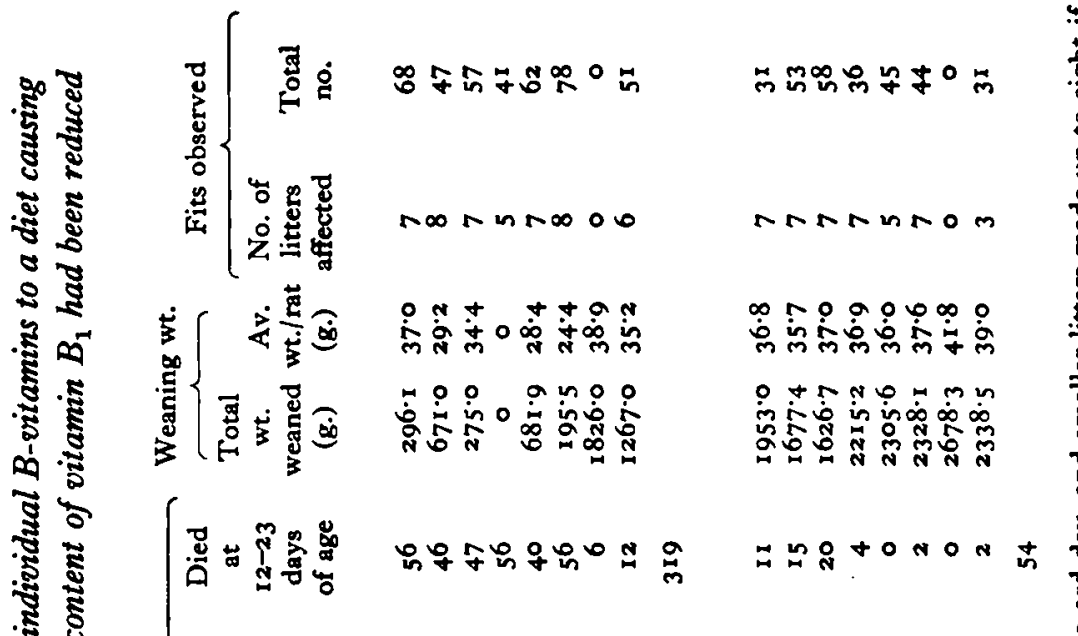

है

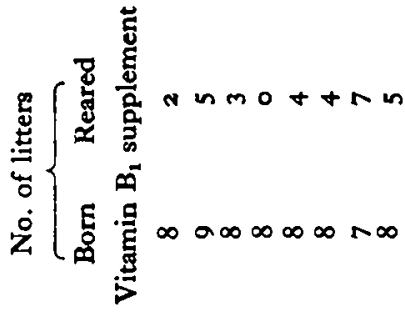

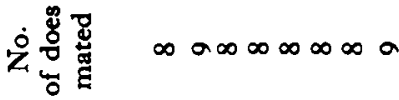

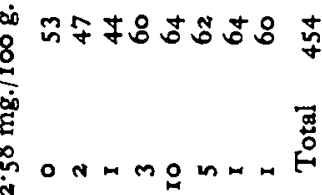
苛

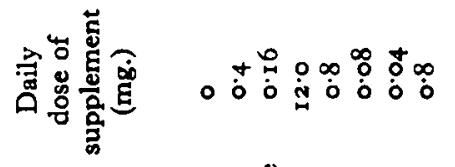

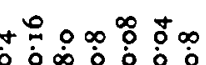

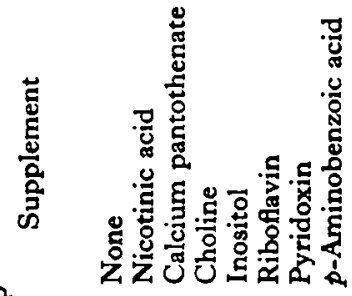
家 0 nd anor

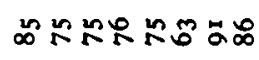

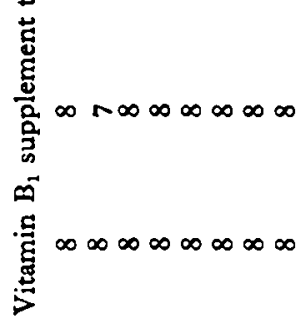

$\infty \infty \infty \infty \infty \infty \infty$

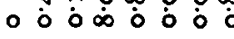

通 है 
invariably, accompanied by screaming, and they may easily be missed if there is no introductory scream to draw attention to them. Small variations in the number of fits observed must therefore be ignored, but with reductions of from sixty-eight to thirtyone, sixty-two to forty-five, seventy-eight to forty-four and fifty-one to thirty-one, it may fairly be concluded that the figures reflect a true decrease in the incidence of fits in the groups with no supplement, and with inositol, riboflavin, and p-aminobenzoic acid. Moreover, in the first breeding test no litter that reached weaning stage, except in the pyridoxin group, failed to show fits. In the second breeding test no fits were noted in three litters of the inositol group or in five litters of the $p$-aminobenzoic acid group, and in each of the other groups one litter seemed to escape fits.

Deaths of sucklings. The total number of rats weaned by mated mothers increased from 154 to 454 , and deaths in the second half of lactation (12-23 days) fell from 319 to fifty-four. The twenty-four mothers of the unsupplemented, calcium pantothenate, and riboflavin groups, which reared in all only twenty-four rats in the first breeding test, succeeded in rearing 159 rats in the second test, and the eight does of the choline group, which reared no young in the first test, reared sixty young in the second, when the vitamin $B_{1}$ and choline intakes were both reduced. In the second test nicotinic acid had no effect in diminishing mortality in the young rats. In fact, the only litter (from eight does) which failed to reach weaning stage belonged to this group, and in another litter only one animal was reared. In the group having the basal diet there were two very poor litters out of eight, with only three or four survivors, and in the pantothenate group one litter out of eight, with only one survivor. Apart from these three groups the number of deaths in the second half of the suckling period was very small, and there were no deaths during this period in the inositol or pyridoxin groups with eight litters in each. Doe 3985 in the pyridoxin group, which had the abnormal litter in the first breeding test, reared a litter of eight in the second test to a weaning weight of $43.3 \mathrm{~g}$.

There are thus many indications from the weaning weights, the occurrence of fits, and the mortality figures, that the conditioned deficiencies, unknown and known, were rendered less severe by the reduction in vitamin $B_{1}$ intake. The improvement from halving the supplement of vitamin $B_{1}$ was much greater than could be accounted for by the greater maturity of the mothers in the second breeding test (cf. Richards, 1949).

\section{Weight of thymus gland of weanlings}

Thymus weights were determined for all the young rats which reached the weaning stage in both breeding tests, but Table 7 includes results only for weanlings of not less than $35 \mathrm{~g}$. in the second breeding test. The choice of $35 \mathrm{~g}$. as the weight below which general atrophy might influence the results is quite arbitrary, and some rejected rats below this weight had a heavier thymus than rats above $35 \mathrm{~g}$. which are included. Results are given for individual litters in each group, and for males and females separately, the number within parentheses after the thymus weight being the number of weanlings included in the estimation.

Table 7 shows that, for rats of weaning weights of $35 \mathrm{~g}$. and over, the averages of the average weights for litters of the thymus glands, expressed in $\mathrm{mg}$./100 g. body-weight, and arranged in ascending order for the different groups were: nicotinic acid r88, 
Table 7. Mean thymus weight of male and female litter-mate weanling rats weighing not less than $35 \mathrm{~g}$. in litters from does receiving a diet low in all B-vitamins except vitamin $B_{1}$ which was present in excess and to which were added individual $B$-vitamins

\begin{tabular}{|c|c|c|c|c|c|}
\hline \multirow[b]{2}{*}{$\begin{array}{c}\text { Group } \\
\text { no. }\end{array}$} & \multirow[b]{2}{*}{ Supplement } & \multirow[b]{2}{*}{$\begin{array}{l}\text { Doe } \\
\text { no. }\end{array}$} & \multicolumn{3}{|c|}{ Mean thymus wt. of litter-mates } \\
\hline & & & $\begin{array}{c}\text { Females } \\
\text { (mg./100 g. } \\
\text { body-wt.) }\end{array}$ & $\begin{array}{c}\text { Males } \\
\text { (mg./roog. } \\
\text { body-wt.) }\end{array}$ & $\begin{array}{l}\text { Whole litter } \\
\text { (mg./ro g. } \\
\text { body-wt.) }\end{array}$ \\
\hline \multirow[t]{5}{*}{$\circ$} & None & $\begin{array}{l}3862 \\
3906 \\
3875\end{array}$ & $\begin{array}{l}243(5) \\
213(3) \\
246(3)\end{array}$ & $\begin{array}{l}188(2) \\
196(2) \\
218(5)\end{array}$ & $\begin{array}{l}227 \\
206 \\
228\end{array}$ \\
\hline & & 3921 & All below $35 \mathrm{~g}$. & - & - \\
\hline & & $\begin{array}{l}3916 \\
3845\end{array}$ & $\begin{array}{l}252(4) \\
\text { All below } 35 \mathrm{~g} \text {. }\end{array}$ & $194(\mathrm{I})$ & 240 \\
\hline & & $\begin{array}{l}3937 \\
3977\end{array}$ & $183(4)$ & $\begin{array}{l}197(2) \\
181(4)\end{array}$ & $\begin{array}{l}197 \\
182\end{array}$ \\
\hline & & Mean & 227 (5 litters) & I 96 (6 litters) & $213 \pm 9$ \\
\hline \multirow[t]{7}{*}{ I } & Nicotinic acid & 3860 & $260(2)$ & $209(5)$ & 224 \\
\hline & & $\begin{array}{l}3846 \\
3902\end{array}$ & $207(2)$ & $\begin{array}{l}188(3) \\
200(5)\end{array}$ & $\begin{array}{l}204 \\
202\end{array}$ \\
\hline & & 3882 & - & $166(2)$ & 166 \\
\hline & & $\begin{array}{l}3939 \\
3831\end{array}$ & $\overline{214(2)}$ & $\begin{array}{l}143(3) \\
178(6)\end{array}$ & $\begin{array}{l}143 \\
187\end{array}$ \\
\hline & & 3987 & No survivors & - & - \\
\hline & & 3852 & I Survivor, $20.8 \mathrm{~g}$. & 一 & - \\
\hline & & Mean & 227 (4 litters) & I8I (6 litters) & $188 \pm 12$ \\
\hline \multirow[t]{7}{*}{2} & Calcium pantothenate & 3854 & $288(4)$ & $252(4)$ & 270 \\
\hline & & 3867 & $112(1)$ & - & 112 \\
\hline & & $\begin{array}{l}3931 \\
3787\end{array}$ & $=$ & $\begin{array}{l}221(2) \\
188(1)\end{array}$ & $\begin{array}{l}221 \\
188\end{array}$ \\
\hline & & 3995 & All below $35 \mathrm{~g}$. & $\overline{2}(5)$ & $\overline{285}$ \\
\hline & & 3954 & I Survivor, $17.5 \mathrm{~g}$. & - & - \\
\hline & & 3907 & I9I (4) & $205(1)$ & 194 \\
\hline & & Mean & 225 (4 litters) & 227 (5 litters) & $212 \pm 26$ \\
\hline \multirow[t]{7}{*}{3} & Choline & $\begin{array}{l}3847 \\
3851\end{array}$ & 二 & $\begin{array}{l}292(1) \\
162(1)\end{array}$ & $\begin{array}{l}292 \\
162\end{array}$ \\
\hline & & 3890 & $178(1)$ & $170(3)$ & 172 \\
\hline & & 3915 & $244(4)$ & I98(4) & 221 \\
\hline & & 3876 & $319(5)$ & $216(3)$ & 280 \\
\hline & & 3859 & $269(2)$ & $307(3)$ & 292 \\
\hline & & $\begin{array}{l}3979 \\
3930\end{array}$ & $\begin{array}{l}281(4) \\
346(4)\end{array}$ & $\begin{array}{l}245(4) \\
400(3)\end{array}$ & $\begin{array}{l}263 \\
369\end{array}$ \\
\hline & & Mean & 273 (6 litters) & 249 (8 litters) & $256 \pm 24$ \\
\hline \multirow[t]{8}{*}{4} & Inositol & $\begin{array}{l}3945 \\
3863\end{array}$ & $326(3)$ & $\begin{array}{l}283(5) \\
267(7)\end{array}$ & $\begin{array}{l}299 \\
267\end{array}$ \\
\hline & & 3855 & $22 I(I)$ & $230(3)$ & 228 \\
\hline & & 3904 & $230(2)$ & $264(3)$ & 250 \\
\hline & & 3994 & 237 (I) & $23 \mathrm{I}(5)$ & 232 \\
\hline & & 3910 & $233(3)$ & $231(2)$ & 232 \\
\hline & & 3993 & $254(4)$ & $251(2)$ & 253 \\
\hline & & 3964 & $279(1)$ & $239(3)$ & 249 \\
\hline & & Mean & 254 (7 litters) & 250 (8 litters) & $25 I \pm 8$ \\
\hline
\end{tabular}

- The figure in parentheses is the number of rats whose thymus glands were weighed. 
Table 7 (cont.)

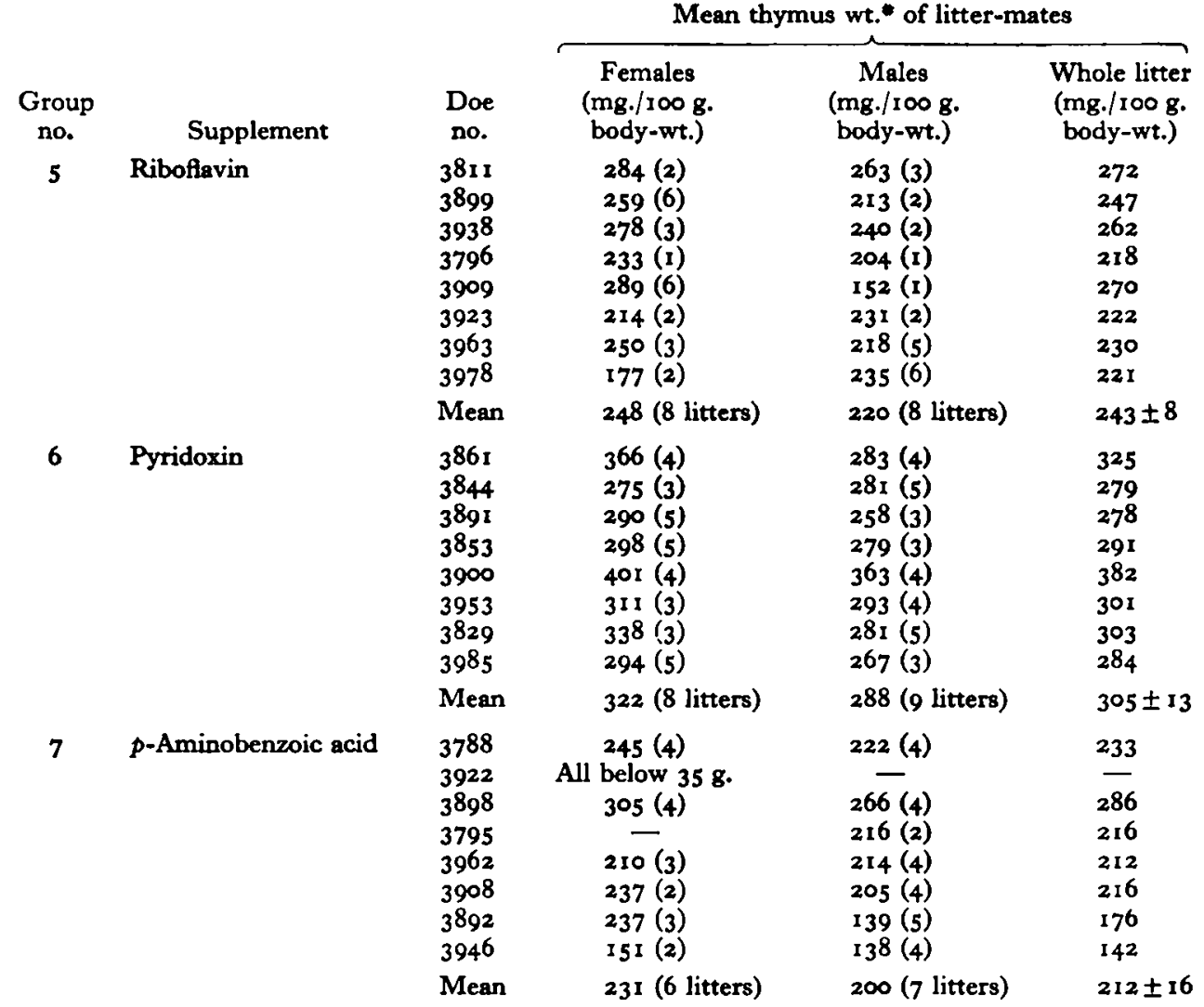

- The figure in parentheses is the number of rats whose thymus glands were weighed.

p-aminobenzoic acid 212, calcium pantothenate 21 2, no supplement 21 3 , riboflavin 243, inositol 25I, choline 256 , and pyridoxin 305 . If rats of weaning weights of $3 \circ \mathrm{g}$. or over are included, the thymus weights are reduced by small amounts ranging from I to $8 \mathrm{mg}$., except in the pyridoxin group, where the value is 306 . It would appear from these results that, under the conditions of this experiment with high vitamin $B_{1}$ intake, addition of nicotinic acid, $p$-aminobenzoic acid and calcium pantothenate had no effect in increasing thymus development. The most marked effect was produced by pyridoxin, and the results appear to indicate a specific effect of this vitamin in promoting development of the thymus. Intermediate values for the thymus were obtained in the riboflavin, inositol and choline groups. The increases in the riboflavin and inositol groups over those in the group without supplement are statistically significant, but the increase in the choline group, in which the average thymus weight was equal to that of the inositol group, is of doubtful significance, in view of the wide variation in the individual results. The thymus weights for the limited number of weanlings which attained a weight of $30 \mathrm{~g}$. in the first breeding test are consistent with the above figures, being for the various groups: nicotinic acid 205, $p$-aminobenzoic acid 205, no supplement 205, calcium pantothenate 176 , inositol 232 and pyridoxin 292. The superiority 
of the pyridoxin group is evident. No figures were available for the choline and riboflavin groups; of the others, inositol was the only supplement which gave any indication of a positive effect.

The average thymus weights in the pyridoxin group of the present test are lower than the figure of 350 , regarded as normal from earlier work, and this further confirms the suspicion that the general intake of factors of the vitamin $B$ complex in this experiment was less than usual. There is little doubt that certain vitamin B factors other than pyridoxin are concerned in thymus development (Stoerk, Eisen \& John, 1947), and deficiency of them would retard the growth of the gland even when the intake of pyridoxin was ample. We do not yet know what may be regarded as the optimum development of the thymus in weanling rats but, since the highest weights were found on a diet containing a high proportion of yeast, the value of $35^{\circ}$ may still be too low to be accepted as normal. Dutra \& McKibbin (1945) found marked atrophy, or even complete absence, of the thymus gland in puppies on a choline-deficient diet, but the histological picture they describe differs from that presented by the glands of weanling rats suffering from the induced pyridoxin deficiency of the present experiments. 'The thymus tissue of the puppies showed few thymocytes in the medullary portion, whereas a marked reduction in the thymocytes of the cortical tissue was the chief feature in the pyridoxin-deficient rats. Although the increased thymus weight in the choline group is not considered statistically significant, it is of interest that five of the fourteen results in columns 4 and 5 of Table 7 range from 292 to $400 \mathrm{mg}$., values comparable with those in the pyridoxin group. In view of the results of Dutra \& McKibbin (1945) the occurrence of these high figures suggests that the action of choline on thymus development merits further study. A combined supplement of pyridoxin and choline given in the conditions of the present experiments might yield interesting results.

\section{DISCUSSION}

\section{Specific effect of pyridoxin on thymus development in suckling rats}

Stoerk \& Zucker (1944) and Stoerk (1946) showed that pyridoxin has a specific effect on thymus development in young rats after weaning. Stoerk showed that in rats 8 weeks old, exposed to a number of adverse dietary conditions, the relationship between the amounts of deficit in body-weight and in thymus weight was in general approximately linear. In pyridoxin deficiency, however, the deficit in thymus weight was much greater than might have been expected from the deficit in body-weight, and only in pyridoxin deficiency was advanced atrophy of the thymus observed without a corresponding marked effect on body-weight. The present results indicate that the specific effect of pyridoxin on the thymus is exerted even in the stage of development before weaning. Whether the occurrence of fits and the atrophy of the thymus are connected with one another, or represent two separate effects of pyridoxin deprivation, is not known, but atrophy of the thymus gland appears to be the surer indication of deficiency, since it may be found even in well-grown weanlings which have shown no outward sign of lack of pyridoxin. 
SUMMARY

1. Young rats of both sexes received from weaning the diet containing chalk, with excess of vitamin $B_{1}$, and low in other B-vitamins, which induced a conditioned deficiency of pyridoxin as previously described (Richards, 1945). The conditioned deficiency was intensified by a further increase in the intakes of vitamin $B_{1}$ and chalk. The rate of growth of the rats was not affected by doubling the vitamin $B_{1}$ supplement, but it was retarded by trebling the calcium supplement and the animals when adult showed permanent injury from prolonged ingestion of the unbalanced diets. Both males and females suffered from fits which could not be cured by subsequent administration of pyridoxin, and the breeding capacity of the females was seriously impaired, particularly in the group with the highest intakes of vitamin $B_{1}$ and chalk.

2. With a few females which had suffered less severely it was possible, by alternately administering and withholding pyridoxin, to obtain apparently normal litters alternating with litters which showed the characteristic fits of pyridoxin deficiency. Marked atrophy of the thymus was found at weaning in the deficient litters, in contrast with the welldeveloped glands of the young reared by the same doe when given a supplement of pyridoxin.

3. The thymus atrophy found in pyridoxin-deficient weanlings was not part of a general atrophy due to malnutrition, but was present in well-developed animals. Over a range of weaning weights of about 37-54 g., the average thymus weight for pyridoxin-deficient animals was $201 \mathrm{mg} . / 100 \mathrm{~g}$. body-weight, whereas the value for weanlings in groups where the mother had received a supplement of pyridoxin or yeast was $344 \mathrm{mg}$., over the same range of weaning weights.

4. This effect of pyridoxin on the thymus development of the weanlings appeared to be specific. When other factors of the vitamin $B$ complex were added singly to a diet of high vitamin $B_{1}$ content under similar conditions, little or no effect on the thymus weight of weanlings was produced by adding nicotinic acid, calcium pantothenate, or $p$-aminobenzoic acid, and the effect of riboflavin, choline and inositol, which did increase thymus weight to some extent, was much less marked than that of pyridoxin.

5. Although some of the experimental data suggest that deficiencies other than of pyridoxin may have been produced by the high vitamin $B_{1}$ intake, the evidence appears to indicate a particular involvement of pyridoxin. Thus pyridoxin had a marked effect in increasing the growth rate of young rats after weaning, whereas relatively little difference was produced by the addition of any of the other vitamin B factors tested, and in the breeding tests the pyridoxin supplement entirely prevented the fits which were observed in the litters of all the other groups. That the high vitamin $B_{1}$ intake was mainly responsible for creating the pyridoxin deficiency was substantiated by the remarkable improvement effected by reducing it. When the vitamin $B_{1}$ supplement was halved there was a considerable diminution in the number of fits, a very marked decrease in the number of deaths during suckling, and a notable increase in the weaning weights of the survivors.

I have much pleasure in thanking $\mathrm{Mr}$ M. H. Quenouille, Lecturer in Statistics, Aberdeen University, for statistical analysis of the results. 
Dutra, F. R. \& McKibbin, J. M. (1945). F. Lab. clin. Med. 30, 301.

Richards, M. B. (1945). Brit. med. $\mathscr{Y} . \mathrm{i}, 433$.

Richards, M. B. (1946). Biochem. F. 40, liii.

Richards, M. B. (1949). Brit. $\mathcal{~}$. Nutrit. 3, 132.

Stoerk, H. C. (1946). Proc. Soc. exp. Biol., N.Y., 62, 90.

Stoerk, H. C., Eisen, H. N. \& John, H. M. (1947). F. exp. Med. 85, 365.

Stoerk, H. C. \& Zucker, T. F. (1944). Proc. Soc. exp. Biol., N.Y., 56, 151.

\title{
Influence of the Extraction Rate of Flour on Conditioned Pyridoxin Deficiency in Rats
}

\author{
BY MARION B. RICHARDS \\ Rowett Research Institute, Bucksburn, Aberdeenshire
}

(Received 30 August 1948)

In experiments previously reported (Richards, 1945), a conditioned pyridoxin deficiency was produced in rats with a diet of high vitamin $B_{1}$ content. The diet was satisfactory for growth and reproduction, but during lactation convulsive fits characteristic of pyridoxin deficiency were observed in the young rats. The fits were prevented by giving the does $40 \mu \mathrm{g}$. of pyridoxin daily from parturition onwards. The basal diet contained $60.9 \%$ of white flour of approx. $70 \%$ extraction, and it was found that the fits were prevented also when $85 \%$ extraction flour was substituted for the white flour. Fig. I gives the weight graphs of litters which show the effect of this substitution on a few does in groups V and VI of the original experiments (Richards, 1945), in which the vitamin $B_{1}$ supplements were, respectively, 0.76 and $5.15 \mathrm{mg} / 100 \mathrm{~g}$. diet, and the calcium supplement $0.54 \mathrm{~g}$. calcium carbonate/ $100 \mathrm{~g}$. diet. In group $\mathrm{V}$, with a medium vitamin $B_{1}$ content, in which fits had been observed frequently in the litters of does on the white flour diet, does 321 and 352 on $85 \%$ extraction flour reared litters free from fits to a good weaning weight. A similar result was obtained even in group VI with the highest intake of vitamin $B_{1}$, where the weight graph of the litter of doe 475 on $85 \%$ extraction flour makes a striking contrast with the almost complete failure of the litters on the white flour diet.

As a sequel to this observation on the effect of substituting $85 \%$ extraction flour for white flour in the diet with the imbalance of B-vitamins, a series of experiments was carried out with flours whose extraction rate ranged from 72 to $85 \%$, all prepared from the same sample of wheat. The studies on growth, reproduction and lactation were continued eventually to the fourth generation. In a preliminary communication (Richards, 1946) a brief report was given of the growth test and first breeding test of first generation rats on the various diets, and another communication (Richards, 1947) outlined the results of the breeding tests of the second and third generation animals. The present paper gives these results in greater detail, including the effect on thymus development in the weanlings, and extends them to include the fourth generation. 